\title{
Erzincan İli Çayırlı İlçesinde Tespit Edilen Tarihi ve Arkeolojik Merkezlerin Değerlendirmesi ${ }^{1}$
}

\author{
İbrahim ÜNGÖR ${ }^{2}$ ve Rıdvan TORUN ${ }^{3}$
}

\section{Öz}

1998 yllından bu güne Erzincan'da sürdürülen yüzey araştırmaları hem Erzincan tarihi hem de Doğu Anadolu'nun tarihi açısından önemli ve yeni sonuçlara ulaşmamızı sağlamıştır. Erzincan'ın doğusunda yer alan Çayırlı ilçesi konumu itibari ile bölgenin siyasi ve kültürel gelişiminde stratejik bir yerdedir. Çayırlı yüzey araştırmalarında tespit edilen arkeolojik ve tarihi merkezler, yerleşim biçim ve tarihi açısından Kuzeydoğu Anadolu ve Erzincan geneline paralel şekilde Kalkolitik Çağ’ın sonlarından başlamaktadır. Çayırlı'da İlk Tunç Çağı ile birlikte yerleşme ve kalelerin sayısında önemli artış olduğu tespit edilmiştir. Bölgenin erken dönem kültürünü ifade eden Karaz Kültürü’ne ait merkezlerinin tespit edilmiş olması ayrıca önemlidir. Yine bilimsel çalışmalarımız ile Erken Demir Çağı ve sonrasında Demir Çağ1 Urartu merkezlerinin tespit edilmiş olması, Urartu Devleti'nin kuzey sınırlarının ve kültürel yayılımının açılanması açısından son derece önemli olmuştur. Çayırlı'da bulunan Sırataşlar Kalesi bunun en güzel örneklerindendir. Çayırlı ilçesine oldukça yakın olan Tercan ilçesi Çadırkaya beldesinde bulunan Çadırkaya/Pekeriç Kalesi, Demir Çağı ve Orta Çağ, Tuzla Kalesi ise Erken Demir Çağı ve Demir Çağı'nda iskân edilmiştir. Yine Orta Çağ’da Çayırlı ve çevresinin oldukça yoğun bir şekilde yerleşim gördüğü yüzey araştırmalarımızın bir sonucu olarak ortaya çıkmıştır. Ayrıca Çayırlı ve çevresinin doğal ve tarihi yolların güzergâhı üzerinde olduğu önemli tespitlerimiz arasındadır. Çayırlı'nın, Erzurum üzerinden gelerek Doğu Karadeniz Bölgesi'nin sahillerine kadar ulaşan yolların merkezinde yer aldığının tespit edilmiş olması önemli olmuştur.

Anabtar Kelimeler: Erzincan, Çayırlı, Diauehi, Karaz, Urartu

\section{Evaluation of the Historical and Archaeological Centers Identified in Çayırlı District of Erzincan Province}

\section{Abstract}

The surface surveys carried out in Erzincan since 1998 and to this day have allowed us to reach important and new results both in terms of the history of Erzincan and the history of Eastern Anatolia. Çayırlı district, located in the east of Erzincan, is a strategic place in the political and cultural development of the region due to its location. The archaeological and historical centers which identified during the surveys starts from the Calcholitic age in terms of the settlement style and historically parallel of Northeastern Anatolia and Erzincan region. Since the Early Bronze Age many settlements and forts appears in Çayırlı. Also, it is important that some settlements has been identified belongs to Karaz culture which reflects the early culture of the region. In addition to this, identification of the Urartian centers with our surveys is important that northern frontiers of the Urartian State during the Iron Age. The Sırataşlar fort which located in Çayırll is one the great example of this. Tercan discrict (which is very close to Çayırll), while Çadırkaya/Pekeriç fort has been inhabited during the Iron and Middle ages, Tuzla fort has been only inhabited early Iron age and Iron ages. Also, our survey shows that intensive settlements can be seen in Çayırll and its vicinity during the Middle age. Further, Çayırlı and its vicinity stationed on the natural and historical roads according to our another observation. It has been important that Çayirlı is located in the center of the roads that come from Erzurum and reach the coasts of the Eastern Black Sea Region.

Key Words: Erzincan, Çayırlı, Diauehi, Karaz, Urartian

\section{Atıf İçin / Please Cite As:}

Üngör, İ. ve Torun, R. (2021). Erzincan ili Çayırlı ilçesinde tespit edilen tarihi ve arkeolojik merkezlerin değerlendirmesi. Manas Sosyal Araştırmalar Dergisi, 10(ÖS), 95-112.

Geliş Tarihi / Received Date: 18.10 .2021

Kabul Tarihi / Accepted Date: 24.11.2021

\footnotetext{
1 Bu çalışma Alpaslan Ceylan başkanlığında yürütülen Erzincan Yüzey Araştırmaları ve Erzincan Binali Yıldırım Üniversitesi Sosyal Bilimler Enstitüsü Tarih Anabilim Dalı’nda, Doç. Dr. İbrahim Üngör danışmanlığında Rıdvan Torun tarafından hazırlanan, “Çayırlı İlçesi ve Çevresinin Eskiçağ Tarihi” başlıklı yüksek lisans tez çalışması temel alınarak hazırlanmıştır.

2 Doç. Dr. - Erzincan Binali Yıldırım Üniversitesi, Fen-Edebiyat Fakültesi, ibrahimungor@gmail.com

(iD) ORCID: 0000-0002-4600-0933

${ }_{3}^{3}$ Doktora öğrencisi - Erzincan Binali Yıldırım Üniversitesi, ridvantorun@yandex.com

(iD ORCID: 0000-0002-1414-6508
} 


\section{Giriş}

Erzincan ili Doğu Anadolu Bölgesi’nin kuzeybatısında yer almaktadır. Eskiçağ’dan günümüze kadar kullanılan tarihi ve doğal yol güzergâhlarına sahip olması, Erzincan tarihinin ve yerleşim kültürünün şekillenmesi açısından çok önemli olmuştur. Bölgenin oldukça engebeli bir yapıya sahip olması dezavantajı bir durum olarak değerlendirilebilir. Buna rağmen Erzincan'ın doğusundan batısına, kuzeyinden güneyine uzanan dağlık alanlarda oluşan vadiler ve Erzurum'dan kaynağını alıp Tercan, Çayırlı, Erzincan, Kemah, İliç ve Kemaliye ilçelerini geçip güneye akan ve Basra Körfezi'ne kadar ulaşan Karasu Irmağı hattında oluşan tarihi ve doğal yollar, Erzincan ve çevresini her zaman önemli geçiş bölgesi yapmıstır. Askeri, ticari ve siyasi amaçlar ile kullanılmış olan bu yollar, Erzincan'ın ilgi çekici ve yerleşim açısından çok tercih edilen bir yer olmasını sağlamıştır. Elimizdeki bilimsel veriler bölgenin Geç Kalkolitik Çağ’dan itibaren yerleşim gördüğünü göstermektedir. Erzincan ve çevresinin Kalkolitik Çağ öncesi hakkında bilgilere henüz sahip değiliz. İleriki dönemlerde prehistoryacılar tarafindan yapılacak çalışmalar ve elde edilecek yeni veriler ile Kalkolitik Çağ öncesi dönemler hakkında yeni bilgiler elde edileceğine inanmaktayız ${ }^{4}$. Kalkolitik Çăg'dan sonra İlk Tunç Çağı'ndan itibaren bin yıl kadar etkili olan Karaz Kültürü izleri Erzincan genelinde çok sayıda merkezde tespit edilmiştir ${ }^{5}$ (Harita. 1). Bu kültürün en belirleyici özelliği olan el yapımı gri, siyah ve devetüyü renklerinde ve parlak yüzeyli keramikler il genelinde yapılan yüzey araştırmalarında çok sayıda merkezde tespit edilmiştir ${ }^{6}$. Erzincan ve çevresinin Eskiçağ Tarihi'ne baktığımızda; Son Tunç Çağı’nda Hititler ile mücadelelerinden tanıdığımız Azzi-Hayaša Devleti'nin ortaya çıktığı görülmektedir. Bu devletin bölgedeki varllğı hakkında ise Hitit metinlerinden bilgi edinilmektedir. Hitit yazılı belgelerinde geçen AzziHayaša dönemi yer isimleri bir kaçı dışında çok belirgin değildir. Erzincan ilinin çevresi ile birlikte AzziHayaša sınırları içinde önemli bir bölümünde yer aldığı kabul edilebilir görülmektedir (Üngör, 2019, s. 5673; Bozgun, 2016, s. 113-126; Üngör ve Özgül, 2016, s. 267-289; Yakar, 2012, s. 374; Garstang, 1943, 48. vd; Friedrich, 1930, s. 103; Güterbock, 1956, s. 41 vd; Pehlivan, 1991, s. 22-39). Erken Demir Çağ1 başlarında ise bölgede Dayaeni/Diauehi Devleti/Beyliği ortaya çıkmıştır (Loon, 1966, s. 6-7; Ceylan, 2017, s. 517-568. Pehlivan, 1984, s. 1-2; Tarhan, 1978, s. 18) (Harita. 2). Özellikle Yoncalı Yazttı'nda adı geçen Dayaeni/Diauehi, Erzurum ve çevresinde varlığını sürdürmüş̧ür. Yine Erzincan ilinin doğu kesimleri de Diauehi'nin hâkimiyet alanı içinde yer almışır (Ceylan ve Üngör, 2018, s. 56).

Diauehi'nin hâkimiyeti altında olan Erzincan'ın zengin maden kaynaklanı, MÖ 13. yy'da Asur Devleti'nin, MÖ 9. yy'dan itibaren ise Urartu Devleti'nin saldırılarına maruz kalmıştır. Transkafkasya, İran ve Doğu Anadolu'yu içine alan geniş bir coğrafyada hâkim olan Urartu Devleti, daha ziyade ekonomik sebepler ile Diauehi üzerine seferler düzenlemiş ve bu devletin elinde bulunan toprakları kendi sınırlarına katarak Diauehi'nin siyasi varllğına son vermiştir (Ceylan, 2017, s. 521-522; Ceylan ve Üngör, 2018, s. 5356; Zimansky, 1985, s. 56-58) (Harita. 3). Erzincan ve çevresinde Urartu Devleti'ne ait ilk izlere Altıntepe Kalesi'nde rastlanmıştır. İlk olarak Von Der Osten bu kalede incelemelerde bulunmuştur. Daha sonrasında Tahsin Özgüç başkanlığında ilk dönem kazı çalısmaları 1959-1968 yılları arasında yapılmıştır. Kazılarda tespit edilen Urartu mimarisine ait kalıntılar ve bulunan küçüklü büyüklü eserler, Urartu Devleti’nin kuzey, kuzeybatı yayılımına ve sınırlarına dair önemli bilgilere ulaşmamızı sağlamıştır. Urartu Devleti, Anadolu'ya kuzeyden giren İç Asyalı Kimmer ve İskit göçleri sonrasında, olası istilaları önlemek ve kuzeybatı güvenliğini sağlamak amacıyla II. Argişti döneminde Altıntepe ve Çadırkaya/Pekeriç gibi bir dizi kaleyi inşa ve tadil ettirmiştir (Osten, 1939, s. 225-229; Ceylan, 2019, s. 27-54; Üngör, 2018, s. 93-129; Özgüç, 1961, s. 253-267; Özgüç, 1963, s. 43-57; Özgüç, 1966, s. 1vdd; Özgüç, 1969, s. 1vdd; Ceylan, 2000a, s. 277-291; Karaosmanoğlu, 2008, s. 69-83).

Erzincan ili ile birlikte Çayırlı ilçesindeki ilk araştırmalar A. Ceylan başkanlığında 1998 yılında başlamış ve halen devam etmektedir. Yapılan araştırmalarda önemli arkeolojik merkezler tespit edilmiş ve bu merkezlerde yapılan bilimsel çalışmalarda önemli bilgiler elde edilmiştir. İlçe sınırlarında bulunan İshak Höyük, Balıklı Köy Kalesi, Çataldaş Kalesi gibi merkezler sahip oldukları konum ve mimari özellikler bakımından oldukça önemlidir (Ceylan, 2000a, s. 277-291). İlçenin sahip olduğu verimli topraklar ve su

\footnotetext{
${ }^{4}$ Erzincan ili genelinde yürütülen yüzey araştırmalarında prehistorik dönemlerde kullanılmış olması muhtemel olan çok sayıda mağara ve kaya sığınağı tarafımızdan tespit edilmiştir. Özellikle Karasu Irmağı çevresi ve Kemah, İliç, Kemaliye gibi iklimi yumuşak olan Erzincan'n güneyindeki bölgelerde yapılacak prehistorik çalışmaların önemine dikkat çekmek isteriz.

${ }^{5}$ Ekibimiz tarafından bu konu ile ilgili çok sayıda bilimsel yayın yapılmışıtır (Ceylan, 2000, s. 277-291; Ceylan, 2002, s. 312; Ceylan, 2003, s. 264; Ceylan ve Üngör, 2018, s. 1 vdd,). Ayrıca Erzincan'ın Karaz Kültürü açısından önemini ve sahip olduğu merkezleri gösteren bir makale de yayına hazırlanmaktadır.

${ }^{6}$ Erzincan ve çevresinde yapılan yüzey araştırmaları sonucunda kuzeybatıda Refahiye Altköy Kalesi, doğuda Tercan Harabetepe Kalesi ve Başbudak Kalesi'nde ve daha çok sayıda merkezde Karaz Kültürü izlerine rastlanılmıştır (Ceylan ve Üngör, 2018, s. 47; Pehlivan, 1984, s. 34 vdd.).
} 
kaynakları, tarım ve hayvancılık faaliyetlerine imkân sağlamış ve Çayırlı ilçesinin sosyo-ekonomik yapısını şekillendirmiştir7. Bölgede yapılan çalışmalar sonucunda tarihi ve arkeolojik nitelik taşıyan 19 merkez tespit edilmiştir ${ }^{8}$. Bu merkezler arasında önemli yere sahip olan kalelerin, bölgenin yönetim merkezi olmasının yanında, verimli toprakları korumak, ilçeden geçen doğal tarihi yolu denetim altına almak gibi birçok işleve sahip oldukları anlaşılmışır (Harita. 4).

\section{Çayırlı İlçesinde Tarihi ve Arkeolojik Araştırmalar ve Tespit Edilen Merkezler}

Erzincan'da tarihi ve arkeolojik çalışmalar; 1938 yılında bir yol çalışması esnasında Altıntepe'de bir prens mezarının tesadüfen keşfi ile başlamıştır. Daha sonraki dönemlerde Von der Osten bulunan bu mezarın Urartu Devleti'ne ait olduğu tespit etmiştir. 1959 yllında bölgede arkeolojik kazı çalışmaları başlamıştır. Tahsin Özgüç başkanlığındaki ekip Altıntepe'de ilk arkeolojik kazıları başlatmış ve 1968 yılına kadar kazı çalışmaları devam etmiştir?. İlk dönem kazılarından sonra 2003 yılında, Mehmet Karaosmanoğlu tarafindan kalede ikinci dönem kazıları başlatılmış ve hâlen devam etmektedir. Yeni kazı çalısmalarında elde edilen buluntu ve elde edilen bilimsel bilgiler, ekip başkanı ve ekip üyeleri tarafindan yayımlanmaktadır (Osten, 1939, s. 225-229; Özgüç, 1961, s. 253-267; Özgüç, 1963, s. 43-57; Özgüç, 1966, s. 1vdd; Özgüç, 1969, s. 1vdd; Ceylan, 2000a, s. 277-291; Karaosmanoğlu, 2008, s. 69-83; Karaosmanoglu, Korucu ve Yllmaz, 2010, s.1vd).

Çayırlı ilçesindeki ilk araştırmalar ise A. Ceylan başkanlığında 1998 yılında başlamış ve günümüzde devam etmektedir. Yapılan çalışmalar sonucunda tespit edilen arkeolojik merkezlerde önemli verilere rastlanılmıştır. Bu dönemde yapılan çalışmalarda Çayırlı sınırları içinde ve yakın çevresinde bulunan Ozanlı Kalesi, Pekeriç Kalesi, İshak Höyük, Balıklıköy Kalesi, Çataldaş Kalesi ve Başköy Kalesi Çayırlı ve bölgenin tarihini aydınlatacak veriler sunmuştur. Özellikle Pekeriç Kalesi’nde tespit edilen kaya işaretleri bilim dünyasının dikkatini çekmiştir. Bu işaretlerin ne anlama geldiği bilim dünyasında tartışlmışır ${ }^{10}$. A. Ceylan başkanlığında gerçekleştirilen yüzey araştırmaları, bölgenin tarihini aydınlatma açısından son dönemin en dinamik bilimsel çalışmalarını oluşturmuştur.

\section{Sayg11 Höyük}

Saygılı Höyük, Çayırlı ilçesinin Saygılı köyünün $1 \mathrm{~km}$ kuzeyinde bulunmaktadır. Höyüğün kuzeygüney uzunluğu $36 \mathrm{~m}$, doğu-batı uzunluğu $47 \mathrm{~m}$, yüksekliği 45 m'dir. Höyüğün kuzey tarafindan bir dere geçmektedir. Höyük konumu itibari ile tarıma elverişli bir arazi içinde bulunmaktadır. Sayglılı Höyük'te iş makineleri kullanılarak kaçak kazı yapıldığı ve bu kazının höyükte ağır tahribata sebep olduğu tespit

\footnotetext{
7 Erzincan ili genelinde yapılan tarımsal faaliyetler, bölgenin en önemli geçim kaynaklarından birini oluşturmaktadır. Farklı dönemlerde bölgeyi ziyaret eden seyyahların eserlerinden bölgenin tarımsal faaliyetleri hakkında önemli bilgilere ulaşılmaktadır (Marco Polo, 2015, s. 20-21; Evliya Çelebi, 2013, s. 248-253). Doğu Anadolu Bölgesi’ndeki dağlar, doğu-batı yönünde uzanmaktadır. Bu dağ silsileleri bölgede Van Gölü’nün kuzey kesimlerinde birleşim göstermektedir. Doğu Anadolu’yu tamamen çevreleyen dağlar orojenik kıvrım dağları olarak adlandırılır. Oluşum süreçleri itibarı ile tektonik ve volkanik hareketler neticesinde bölge çok engebeli ve yüksek bir morfolojik yapıya bürünmüştür. Bölgede sismik hareketliğin bulunması, Kuzey Anadolu Fayı'nın (KAF) bölgeden geçmesi Erzincan Ovası ve çevresinin oluşumuna zemin hazırlamıştır (Ketin, 1976, s. 153; Gül ve Başıüyük, 2011, s. 9; Yalçın ve Polat, 2021, s. 1043; Ceylan ve Üngör, 2018, s. 27). Erzincan ili, Doğu Anadolu Bölgesi’nin kuzeybatısında, Yukarı Karasu/Fırat Bölümü sınırları içinde bulunur. Erzincan ili, hem Anadolu'nun iç bölgelerinden kuzey-güney yönlü geçiş noktasında, hem de Anadolu ile Asya içlerine kadar uzanan doğu-batı yönlü tarihi yol ağlarının merkezinde bulunmaktadır (Saraçoğlu, 1989, s. 1 vd.; Tarkan, 1974, s. 7 vdd.; Gül ve Başıüyük, 2011, s. 7). Çayırlı ilçesi ile birlikte Erzincan ilinin Merkez ilçesi, Tercan, Otlukbeli, İliç, Refahiye, Kemah, Kemaliye ve Üzümlü olmak üzere toplam dokuz ilçesi bulunmaktadır. Çayırlı ilçesi, Erzincan il merkezinin doğusunda, il merkezine $113 \mathrm{~km}$ uzaklıkta bulunmaktadır. Çayırlı ilçesi; Esence Dağları'nın kuzeyinde, Başköy Depresyonu olarak bilinen doğu-batı uzantılı çukur sahanın doğu kesiminde yer alır. Çayırlı ortalama $1500 \mathrm{~m}$ rakıma sahiptir. İlçenin en yüksek noktasını oluşturan Esence Dağları $3.546 \mathrm{~m}$ rakıma sahiptir. İlçe merkezi 33 km² lik bir ovanın içinde bulunur. Ovanın eğimi, kuzeybatı yönünden güneydoğu yönüne doğrudur. Ova batı ve güneybatı yönünden Esence Dağları, Kuzeyde ise Otlukbeli Dağları ile çevrilidir. Ova 3 ana bölümde incelenmektedir. 1. bölüm Saygılı Düzü 2. bölüm Balıklı Çayı ve ilçe arasındaki alan 3. bölüm ise Harmantepe Düzü'dür (Ceylan, 2000, s. 277; Akkan, 1963, s. 92; Ceylan, 2019, s. 636; Korkmaz, 2015, s.224). Çayırlı ilçesinin içinde yer aldığı ova, Erzincan Ovası’na göre tepelerle bölünen daha arızalı bir yapıdadır. İlçenin iklim şartları ve topoğrafik özellikleri bitki çeşitliliği ve verimliliği için uygun ortamı oluşturur (Polat ve Yalçın, 2020, s. 125-150; Gül ve Başıüyük, 2011, s. 18-19).

81998 yılında Erzincan il merkezinde başlatılan ve devam eden tarihi ve arkeolojik yüzey araştırmalarında Çayırlı bölgesinde ve çevresinde tespit edilen yerleşim alanları; Büyük Kalecik Höyük, Beykomu Höyük, Arıtaş Höyük, Saygıll Höyük, Haramidere Yerleşmesi, İshak Höyük, Çataldaş Höyük, Turnaçayırı Kalesi, Başköy Kalesi, Ozanlı Kalesi, Toprak Kale, Kurt Kalesi, Mirzaoğlu Kalesi, Yukarı Kartallı Höyük, Aşağı Kartallı Höyük, Hasanbey Kalesi, Balıklıköy Kalesi, Arıtaş Kalesi, Sırataşlar Kalesi (Ceylan, 2000b, s. 81-192; Ceylan, 2001, s. 71-82; Ceylan, 2002, s. 311-324; Ceylan, 2003, s. 263-272; Bingöl, Ceylan, vd, 2010, s. 375-398).

${ }^{9}$ Bu kazı Erzincan ve çevresinde yapılan ilk bilimsel arkeolojik kazı olmuştur.

${ }^{10}$ Bu konuda ve bilimsel farklı görüşler için bkz (Ceylan ve Üngör, 2018, s. 189-190).
} 
edilmiştir. Köyde yapılan araştırmalarda höyükten çıktı̆̆ı anlaşılan pithos parçaları ile karşılaşılmışır. Kaçak kazı alanlarında yapılan incelemelerde höyüğün yangın geçirdiği anlaşılmıştır. Saygılı köyündeki modern evlerde höyükten çıkarılmış kesme taşlar kullanıldığı görülmüştür. Yapılan araştırmalar sayesinde höyükte İlk Tunç, Demir Çağı ve Orta Çağ keramikleri elde edilmiştir (Ceylan, 2005, s. 23; Ceylan, 2008, s. 76; Ceylan, 2019, s. 639-640) (Foto. 1).

\section{Sırataşlar Kalesi}

Sırataşlar Kalesi, Çayırlı ilçe merkezine 8 km uzaklıkta, ilçenin kuzeydoğusunda yer almaktadır. Kale, konum itibari ile tarım alanlarına yakın ve ovaya oldukça hâkim bir konumdadır. Kalenin batısından Karadivan Çayı geçmektedir. Kalenin bulunduğu yer bol su kaynağına sahiptir. Kale, ana kayaya uygun biçimde, dikdörtgene yakın bir plânda inşa edilmiştir. Kalede ana kaya üzerine yapılan taş işçiliği döneminin en iyi örneklerinden biridir. Kalenin bir kısmını oluşturan kaya yüzeyi perdahlanarak düzleştirilmiştir. Bu kısım sanki yazıt yapımına yönelik hazırlık yapıldığı izlenimi vermektedir. Ancak kale ve çevresinde herhangi bir yazıt ya da kabartmaya rastlanılmamıştır (Ceylan, 2008, s. 73; Günaşdı, 2015, s. 117).

Sırataşlar Kalesi konumu itibari ile çok önemli olduğunu düşündüğümüz tarihi yolların üzerinde bulunmaktadır. Tespitlerimize göre bu yollar; Erzurum hattını takip ederek Urartu Devleti'nin merkezinden Karadeniz sahillerine kadar ulaşmaktadır. Bu yolların güvenliğini ve işlerliğini sağlamak için bir dizi kale ile birlikte Sırataşlar Kalesi’nin inşa edildiğini düşünmek doğru olacaktır. Kalenin konumu ve mimari özellikleri dikkate alındığında Urartu askeri kalesi olma özelliğine sahip olduğunu söylemek mümkün olmaktadır. Bununla birlikte kale, savunma bakımından beklenildiği ölçüde, diğer Urartu kaleleri kadar, güçlü ve ulaşılması zor bir konuma sahip değildir. Bunun nedeni ise; Altıntepe, Pekeriç ve Şirinli Kale gibi güçlü kalelerin birbirine yakın olmasıdır. Bu sayede ortak bir güvenlik ve savunma ağ1 oluşturulmuş olduğunu düşünmekteyiz. Yine Sırataşlar Kalesi'nde ana kaya oyularak yapılan su kanalı ve su tüneli, Erzincan ve Doğu Anadolu'nun diğer bölgelerinde karşımıza çıkan Urartu mimarisinin güzel örneklerinden biridir (Belli, 2000, s. 394-402; Ceylan, 2008, s. 171 vd.; Özgül, 2015, s. 69-92; Karageçi ve Günaşdı, 2019, s. 649-667; Kalmıs, 2020, s. 158). Kalenin duvarları kiklopik teknik ile yapılmıştır. Ayrıca kale içerisinde kutsal bir alan tespit edilmiştir (Ceylan ve Üngör, 2018, s. 90-91; Ceylan, 2001, s. 166; Günaşd1, 2015, s. 117; Ceylan, 2005, s. 23) (Foto 2-3).

\section{Aşağ1 Kartallı Höyük}

Aşağ1 Kartallı Höyük, Çayırlı ilçesinin 18 km güneydoğusunda, Aşağ1 Kartallı köyünün içerisinde yer alır. Höyügün, yerleşim alanının içinde bulunmasına rağmen tahribatın az olduğu görülmüştür. Höyükte yapılan incelemeler esnasında herhangi bir keramik kalıntısına rastlanılmamıştır. Aşağı Kartallı Höyük, Çayırlı ile Tercan ilçeleri arasında doğal yol ağının üzerinde önemli bir konumda yer almaktadır. Aşağı Kartallı Höyük, Mercan-Çadırkaya-Çayırlı-Otlukbeli-Demirözü güzergâhını izleyerek Bayburt'a ve sonrasında ise Karadeniz sahillerine kadar uzanan doğal yol ağının üzerinde bulunması açısından önem taşımaktadır (Ceylan, 2003, s. 264; Torun, 2021, s. 61).

\section{Balıklıköy Kalesi}

Çayırlı ilçe merkezine $4 \mathrm{~km}$ mesafede bulunan kale, adını aldığı Balıklı köyünün içinde yer almaktadır. Kale, 1.20 x 1.80 ölçülerinde taşlarla örülü bir duvar yapısına sahiptir. Kalede görülen yapım tekniği Orta Çağ mimarisinde görülen moloz taş örgü sistemiyle oluşturulmuştur. Kalenin kurulu olduğu ana kayanın taş ocağı olarak kullanıldığ1 tespit edilmiştir. Balıklıköy Kalesi’nin, bölgeyi ve tarihi yol ağının geçiş güvenliğini sağlamak amacıyla kullanılan bir Orta Çağ kalesi olduğu tespit edilmiştir (Ceylan ve Üngör, 2018, s. 84) (Foto 4).

\section{Tuzla Kalesi}

Tuzla Kalesi, Esence ve Munzur Dağları'nın doğu ucunda, Otlukbeli Dağları arasında kalan alanda Çadırkaya beldesinin $3 \mathrm{~km}$ güneydoğusunda yer almaktadır. Kayalık bir tepe üzerine inşa edilen kale, Karasu Irmağı'na $5 \mathrm{~km}$ mesafededir. Çevresi verimli tarım arazileri ile çevrilidir. Kale, Erzurum-AşkaleTercan ve yine Erzurum-Çat-Şirinli Kale-Tercan üzerinden gelen tarihi doğal yolların geçiş güzergâhına hâkim bir konumda yer almaktadır (Üngör, 2018, s. 104-105; Üngör ve Özgül, 2016, s. 267-289). Tuzla Kalesi, üzerine kurulduğu tepenin morfolojisine uygun olarak Kuzeydoğu-güneybatı yönünde inşa edilmiştir. Tuzla Kalesi'nin özellikle Orta Demir Çağı'nda Urartular tarafından; Pekeriç Kalesi, Şirinli Kale ve Altıntepe Kalesi ile birlikte bölgenin yönetimi ve güvenliği açısından son derece önemli bir fonksiyona sahip olduğunu söylemek doğru bir tespit olacaktır. Kalenin en önemli işlevlerinden birinin tarihi doğal 
yolların güvenliğini sağlamak olduğu açıktır. Bu nedenle tarihi yol ağlarının merkezinde bulunan Tercan Ovası'nın tamamını kontrol edebilecek kadar önemli bir yerde kurulmuştur. Kalenin çevresi yoğun olarak tarım için kullanılmaktadır. Kale hayvancılık açısından da oldukça elverişli bir alanda, dağlarla çevrili bir konuma sahiptir. Kalede, ana kaya oyma yöntemiyle yapılmış, 18 adet kaya basamağı ile ulaşılabilen bir kutsal alan tespit edilmiştir. Bu tür kutsal alanların benzerlerine Erzincan Sırataşlar Kalesi ve Erzurum Avnik Kalesi'nde rastlanılmaktadır (Günaşdı, 2016, s. 113-135, Ceylan, 2008, s. 171vd.; Ceylan, 2015, s. 302vd). Ayrıca kalenin farklı yerlerinde sunaklar da tespit edilmiştir (Üngör, 2018, s. 105-106; Günaşdı, 2015, s. 113-131; Günaşd1, 2016, s. 113-135).

Kalede yaptığımı incelemelerde çok miktarda İlk Tunç Çağı, Erken Demir Çağı, Orta Demir Çağı ve Orta Çağ keramikleri tespit edilmiştir. Keramik verileri incelendiğinde, kalenin ilk olarak İlk Tunç Çağı’nda inşa edildiğini düşünmekteyiz. Erken Demir Çağı'nda Diauehi ve Urartuların bölgede hâkim olduklarını, Orta Demir Çağı döneminde merkezi bir kale olduğunu söylemek mümkündür (Ceylan ve Üngör, 2018, s. 224-226; Üngör, 2018, s. 93-129) (Foto. 5-6/Çizim. 1).

\section{Çadırkaya/Pekeriç Kalesi}

Çadırkaya Kalesi; Erzincan ilçe merkezine $104 \mathrm{~km}$ uzaklıkta, Tercan ilçesi sınırları içerisinde bulunmaktadır. Kale, Çayırlı ilçe sınırlarına oldukça yakın bir mesafede, ilçenin kuzeydoğusunda Çadırkaya beldesinin içerisinde konumlanmaktadır. Çadırkaya Kalesi'nin, Urartu Devleti krallarından II. Arğişti döneminde, Kimmer akınlarına karşı bölgenin savunmasına ve Altıntepe ile birlikte yönetimine destek sağlamak amacıyla kurulmuş olabileceğini düşünmekteyiz. Kalede on dokuz adet Urartu kaya mezarı ile kaya basamaklı su tünelleri bulunmaktadır. Ayrıca su, şarap ve yă̆ gibi ürünlerin korunmasını ve depolanmasını sağlamak amacıyla ana kaya oyularak inşa edilmiş bir sarnıç bulunmaktadır (Ceylan, 2019, s. 33; Ceylan, 2000a, s. 278-279).

Çadırkaya Kalesi, Urartu kaya işaretlerinin en güzel örneklerinin olduğu kalelerden biridir. Kalede yer alan kaya işaretleri kalenin güney etek kısmında bulunan kayalık alanda yer alır. Biçim bakımından "V", "U", "daire" şeklindeki kaya işaretlerinin ne için yapıldığı aydınlığa kavuşmuş değildir (Konyar, 2008, s. 310-312). Kaya işaretleri ile ilgili genel kanı işaretlerin, ritüelik ve mistik bir anlamı olduğu yönündedir. E. Konyar bu konuda farklı bir düşünce ortaya koymuştur. Konyar'a göre bu işaretler tekerlek ve benzeri araç gereçleri üretmek için kalıp olarak kullanılmıştır. Bize göre ise kaya işaretlerin bulunduğu alanın kalenin dış bölümünde yer almış olması, şekillerin tekerlek ve boyunduruk biçimine uygun olması bu görüşü destekler mahiyettedir (Ceylan, 2019, s. 27-54; Konyar, 2008, s. 310-320). Çadırkaya Kalesi ile ilgili elde bulunan bilgiler değerlendirildiğinde; kalenin Orta Demir Çağı'nda çok önemli bir yönetim, savunma ve üretim merkezi olduğu açıkça ortadadır. Ayrıca bu kale Orta Çağ’da da önemini korumuş görünmektedir (Ceylan, 2000a, s. 278-279) (Foto. 7-8).

\section{Beykomu Höyük}

Beykomu Höyük, Çayırlı ilçe merkezinin 12 km kuzeydoğusunda yer alır. Höyüğün doğu-batı genişliği 14 m, kuzey-güney genişliği ise 13 m'dir. Höyük Çayırlı Ovası'na hâkim bir tepe üzerinde bulunmaktadır. Ovadan $50 \mathrm{~m}$ daha yüksekte bulunan Beykomu Höyük'ün üzerinde bulunduğu tepe kum tepesi özelliği göstermektedir. Höyük, Karasu Irmağı'nın suladığı Çayırlı Ovası'nın verimli alanlarının içinde bulunmaktadır. Höyükten elde edilen keramikler İlk Tunç Çağı, Demir Çağı ve Orta Çağ dönemlerine aittir (Ceylan, 2008, s. 77) (Foto 9).

\section{Haramidere Yerleşmesi}

Haramidere Yerleşmesi, Çayırlı ilçe merkezinin $10 \mathrm{~km}$ kuzeydoğusunda yer almaktadır. Geniş bir sahaya yayılan yerleşme, dağ silsilelerinin doğu eteğinde konumlanmaktadır. Haramidere Yerleşmesi’nin, kuzeyinden Karasu Irmağı ve Çayırll-Mercan karayolu geçmektedir. Yerleşme konumu itibari ile ovaya oldukça hâkim bir konumdadır. Haramidere Yerleşmesi’nde gerçekleştirilen yüzey araştırmalarında, kaçak kazıların yapıldığı anlaşılmıştır. Kaçak kazılar sonucunda ortaya çıkan alan incelendiğinde yerleşmenin yangın geçirdiği anlaşılmıştır. Çayırlı bölgesinde bulunan en zengin keramik malzemelerini bu yerleşme vermektedir. Haramidere Yerleşmesi'nden elde edilen keramikler İlk Tunç Çağı, Erken Demir Çağı, Demir Çağ1 ve Orta Çağ dönemlerine tarihlenmektedir (Ceylan, 2008, s. 77) (Foto 10). 


\section{Sonuç}

Erzincan il merkezi ve ilçelerinde sürdürülen yüzey araştırmaları neticesinde çok sayıda kale, höyük, baraj, gölet, mezar sahası (nekropol), maden ergitme sahası ve yerleşim alanı gibi arkeolojik merkezler tespit edilmiştir. Erzincan il genelindeki tarihi ve arkeolojik yüzey araştırmalarına A. Ceylan ve ekibi tarafindan 1998 ylında başlanmıştır. Çayırlı ve çevresinde tespit edilen ve çok yönlü bilimsel çalısmaları yapılan merkezler ve elde edilen bilgiler Çayırlı'nın ve geniş manada bölgenin Eskiçağ Tarihi hakkında son derece önemli bilgiler sağlamıştır.

Çayırlı ilçesinin yer aldığı bölgenin sahip olduğu verimli tarım arazileri ve su kaynaklarının yanı sıra iklim şartlarının elverişli olması ve doğal tarihi yolların üzerinde bulunması, ilçenin tarihi coğrafyasını son derece önemli bir hale getirmiştir. Çayırlı Ovası'nda bulunan ve sularını Karasu Irmağı'na boşaltan çok sayıda akarsu bulunmaktadır. Bu akarsular yerleşim yerlerinin su ihtiyacını karşılaması bakımından oldukça önemlidir. Akarsularla yakın mesafede olan yerleşim yerleri arasında Karasu (Haramidere Kalesi, Beykomu) Çayır Deresi (Arıtaş Kalesi, Arıtaş Höyük), Turnaçayırı Deresi (Turnaçayırı Kalesi), Toprakkale Deresi (Toprakkale Kalesi), Oğultaş Deresi (Toprakkale Kalesi), Karadivan Çayı (Sırataşlar Kalesi) bulunmaktadir.

Yaptığımız bilimsel çalışmalar neticesinde Erzincan ilinin genelinde, Geç Kalkolitik Çağ’dan itibaren çok sayıda merkezde yerleşimin olduğu tespit edilmiştir. Yine bu çalsşmalarda Kalkolitik Çağ'dan sonra bölgede bulunan "Karaz Kültürü”ne ait izlerin arttığ1 saptanmıştır. İlk Tunç Çağ1 ile birlikte bölgede nüfusun ve yerleşim yerlerinin sayısı önemli ölçüde artmıştır. Orta Tunç Çağı’nda bölgedeki yerleşimlerin devam ettiği ve Son Tunç Çağı’nda bölgede Azzi-Hayaša Devleti'nin hâkim olduğu anlaşılmaktadır. Hitit metinlerinden de anlaşıldığı üzere, Erzincan-Erzurum hattı arasında kalan bölgenin çekirdek Azzi-Hayaša olarak belirtilmesi, Çayırlı ilçesinin Azzi-Hayaša Devleti'nin hâkimiyet sahasında olduğu gerçeğini ortaya koymaktadır. Son Tunç Çağı, Erken Demir Çağı ve Orta Demir Çă̆ı'na kadar Çayırlı ve çevresinin Dayaeni/Diauehi Devleti/Beyliği egemenliğinde olduğuna ise şüphe yoktur.

Bölgede yapılan yüzey araştırmaları ile Çayırlı ilçesi ve yakın çevresinde Urartu dönemine ait çok sayıda kalenin varlığının tespit edilmesi ayrıca önemli olmuştur. Bu veriler değerlendirildiğinde, Urartu yayılım sahası içinde bulunan Çayırlı'da, Demir Çağı'nda siyasi yapılanmada önemli değişiklikler olduğu anlaşılmıştır. Bölgedeki varlığını korumak ve dışarıdan gelen saldırıları engellemek maksadıyla Urartu Devleti'nin, Çayırlı ve yakın çevresinde çok sayıda kaleyi tadil ettiği ve yenilerini de inşa ettiği tespit edilmiştir. Urartu mimari geleneğinde yenilenen kalelerin, İlk Tunç Çă̆g'nda inşa edildiği ve Demir Çağı'nda bu kalelerin Urartular tarafından farklı amaçlar ile kullanıldığı anlaşılmıştır. İlçeye yakın bir konumda bulunan ve Demir Çă̆ı'nda inşa edildiği tespit edilen Çadırkaya/Pekeriç Kalesi'nin, Altıntepe Kalesi ile aynı dönemde Urartuların kuzey bölgesinin yönetimini sağlamak amacıyla inşa ettirildiğini düşünmekteyiz. Çadırkaya/Pekeriç Kalesi yakınlarında ve Çayırlı ilçe sınırlarında bulunan küçük çaplı kaleler, hem bölgenin sahip olduğu verimli ovayı hâkimiyet altında tutmak, hem de mevcut merkezi kalelerin güvenliğine destek sağlamak amacıyla kurulmuştur.

Çalışmalarımızda Urartu Devleti’nin bölgede sistemli bir yerleşim politikası izlediği anlaşılmıştır. Urartuların Erzurum ve Erzincan'ı içine alan bölgenin tamamında olduğu gibi; maden kaynaklarını ve su varllğını aktif bir biçimde kullandığ tespit edilmiştir. Bu nedenle ovaları iskân ederek hâkim noktalarda kaleler inşa ettirdikleri ve eskilerini de Urartu mimarisine uygun biçimde tadil ettikleri anlaşılmıştır. Kurulan bu sistemli teşkilat yapısı sayesinde Urartular, eyaletleri ile merkezleri arasında kuvvetli bir bağ kurmuşlardır. Ekonomisi tarım, madencilik ve hayvancıllğa dayanan Urartuların, Çayırlı ilçesinin verimli ovalarını denetim altında tutmak amacıyla yüksek kesimlerde kaleler ve gözetleme kuleleri inşa ettikleri tespit edilmiştir. Yerleşim yerleri ve mimari yapıları değerlendirildiğinde, savunma açısından son derece önemli olan bu kaleler, ticari faaliyetleri de olumlu etkilemiş olmalıdır. Bölgede kurulan sistemli yapının önemli bir parçası olan doğal tarihi yollar geliştirilerek askeri, siyasi ve ticari yol ağı şekline bürünmüştür. Bu anlamda, Stratejik konumları ve mimari özellikleri göz önünde bulundurulduğunda; Çayırlı'da bulunan Haramidere Kalesi ve Saygılı Höyük önemli merkezlerdendir.

Özellikle Altıntepe Kalesi, Çadırkaya/Pekeriç Kalesi, Şirinli Kale, Sırataşlar Kalesi, Tuzla Kalesi, Taşbulak Kalesi gibi kaleler sayesinde Urartu Devleti'nin Erzincan bölgesinde etkin ve kalıcı olması hedeflenmiştir. Çayırlı ilçesinde kurulan kaleler ve yerleşim alanları askeri seferlerde askerlerin ulaşımının sağlanmasında önemli birer lojistik merkez olmuştur. Yerleşim alanlarında üretilen ve ticari değeri olan mallar ve hammaddeler, Urartu ekonomisine önemli ölçüde katkı sağlamış olmalıdır. Kalelerin varlığı, olası bir savaş halinde askeri malzemenin temini ve elde edilen ganimetlerin korunmasında, daha sonra ise 
merkeze gönderilmesinde önemli bir depo vazifesi de görmüştür. Sonuç olarak, yaptı̆̆ımız tüm bilimsel çalışmalar göstermektedir ki: Çayırlı ilçesi İlk Tunç Çağı’ndan itibaren eskiçağ boyunca tarihi ve arkeolojik açıdan bölgenin çok önemli bir coğrafyası olma özelliğini korumuştur.

\section{Etik Beyan}

"Erzincan İli Çayırlı Illçesinde Tespit Edilen Tarihi ve Arkeolojik Merkezlerin Değerlendirmesi”" başlıklı çalışmanın yazım sürecinde bilimsel kurallara, etik ve alıntı kurallarına uyulmuş; toplanan veriler üzerinde herhangi bir tahrifat yapılmamış ve bu çalışma herhangi başka bir akademik yayın ortamına değerlendirme için gönderilmemiştir. $\mathrm{Bu}$ araştırma doküman incelemesine dayalı olarak yapıldığından etik kurul kararı zorunluluğu bulunmamaktadır.

\section{Kaynakça}

Akkan, E. (1964). Eræ̌incan ovası ve çevresinin jeomorfolojisi. Ankara: Ankara Üniversitesi Dil ve Tarih Coğrafya Fakültesi Yayınları.

Belli, O. (2000). Dünya'nın en büyük hidrolik uygarlı̆ğ: Urartular. Türkiye Arkeolojïsi ve İstanbul Üniversitesi (1932-1999) (Ed: O. Belli). Ankara: İstanbul Üniversitesi Yayınları. ss. 394-402.

Bingöl, A., Ceylan, A., vd. (2010). 2008 yılı Erzincan, Erzurum, Kars ve Iğdır illeri Yüzey Araştırmaları. 27. Araştırma Sonuclar Toplantısı, c. 2. Ankara: Kültür Varlıkları ve Müzeler Genel Müdürlüğü Yayını. ss. 375-398.

Bozgun Ş. (2016). İÖ 2. binyılda Hitit çiviyazılı belgelere göre Erzincan ve çevresi. Uluslararası Eræincan Sempozyumu, c. I. ss. 113-126.

Ceylan, A. (2000a). Çayırlı'da tarihi ve arkeolojik araştırmalar. Atatürk Üniversitesi Türkiyat Araştırmalar Enstitüsü Dergisi, 15, 277-291.

Ceylan, A. (2000b). 1998 y1lı Erzincan yüzey araştırması. 17. Araştırma Sonuçar Toplantısı, c. 2. Ankara: Kültür Bakanlığ1 Yayınlar. ss. 181-192.

Ceylan, A. (2001). 1999 yılı Erzincan ve Erzurum yüzey araştırmaları. 18. Araştırma Sonuclar Toplantısı, c. 2, Ankara: Kültür Bakanlığı Milli Kütüphane Basımevi. ss. 71-82.

Ceylan, A. (2002). 2001 yılı Erzincan, Erzurum ve Kars illeri yüzey araştırmaları. 20. Araştırma Sonuclar Toplantısı. 2731 Mayıs. Ankara: Kültür Varlıklar1 ve Müzeler Genel Müdürlügüu. ss. 311-324.

Ceylan, A. (2003). 2002 yılı Erzincan, Erzurum, Kars ve Iğdır illeri yüzey araştırmaları. 21. Araştırma Sonuclar Toplantısı, C: 2. 26-31 Mayıs. Ankara: Kültür Varlıkları ve Müzeler Genel Müdürlüğü. ss. 263-272.

Ceylan, A. (2005). The Erzincan, Erzurum and Kars region in the Iron Age. Anatolian Iron Ages V, London. pp. 2129.

Ceylan, A. (2008). Doğu Anadolu araștırmalar I, Eržurum-Erz̨incan-Kars-Iğdır (1998-2008). Erzurum: Güneş Vakfi Yayınlar1.

Ceylan, A. (2015). Doğu Anadolu araștırmalar II, Eræ̧urum-Erz̨incan-Kars-Iğdır (2008-2014). Erzurum: Atatürk Üniversitesi Yayınları.

Ceylan, A. (2017). Yeni bulgular ışığında Kuzeydoğu Anadolu'da Diauehi Krallı̆̆1 ve Urartular. Kafkas Üniversitesi Sosyal Bilimler Enstitüsü Dergisi, 20, 517-568.

Ceylan, A. (2019). Urartu'da Kaya İşaretli Kalelerden Çadırkaya Kalesi. Uluslararası Eræżincan Sempozyumu (26-28 Eylül 2019) Bildiriler Kitabı. ss. 27-54.

Ceylan, A. ve Üngör, İ. (2018). Eskiçağğda Erz̨incan kaleleri. Erzurum: Atatürk Üniversitesi Yayınları.

Ceylan, N. (2019). Çayırlı Tarihine Işık Tutan Yerleşme: Saygılı Höyük, Kafkas Üniversitesi Sosyal Bilimler Enstitüsü Dergisi, 24, 635-648.

Evliya Çelebi (2013). Günümür Türkçesiyle Evliya Çelebi Seyahatnamesi-1, 1-6. Kitaplar (Çev: S. A. Kahraman-Y. Dağl1), C: 1. İstanbul: Yap1 Kredi Yayınları.

Friedrich, J. (1930). Staatsverträge des Hatti-Reiches in Hethitischer Sprache II, Mitteilungen der vorderasiatisch- ägyptischen Gesellchaft 34/1, Leipzig.

Garstang, J. (1943). Hittite Military Roads in Asia Minor. The Journal of the Archaeological Institute of America, 47, Boston.

Gül, A. ve Başıüyük, A. (2011). Bir Taribi Coğrafya Incelemesi (Osmanlidan Cumburiyet'e Erz̨incan Kaz̧asi). Erzurum: Salkımsöğ̈ut Yayınevi.

Günaşd1, Y. (2015). Erzincan Sırataşlar Kalesi. Trakya Üniversitesi Edebiyat Fakültesi Dergisi, 5(9), 113-131.

Günaşd1, Y. (2016). Geçitler Ülkesinde Önemli Bir Urartu Kalesi: Avnik. TÜBA-AR (19) 113-135.

Günek, H. (2006). Karasu (Fırat) havzasının su potansiyeli ve değerlendirilmesi. Doğg Coğrafya Dergisi, 11(15), 113-136.

Güterbock, H. G. (1956). The Deeds of Suppiluliuma as Told by his Son, Mursili II. JCS X, Boston.

Kalmış, G. (2020). Kuzeydoğu Anadolu Bölgesinde Tespit Edilen Köroğlu Kaleleri. Tokat Gaz̧iosmanpaşa Üniversitesi Sosyal Bilimler Arastırmalar Dergisi, XV(I), 155-169.

Karageçi, M. ve Günaşd1, Y. (2019). Erzurum'da Önemli Bir Urartu Kalesi: Harami Kale. Kafkas Üniversitesi Sosyal Bilimler Enstitüsü Dergisi, 24, 649-667.

Karaosmanoglu, M., Korucu H. ve Yılmaz M. A. (2010). Altıntepe ką̧ ve onarm çalısmalar tanıtım el kitap̧̧ı̆g. Erzincan: Dogu Matbaas1. 
Karaosmanoğlu, M. (2008). Altıntepe Kalesi İkinci Dönem Kazıları. Atatürk Üniversitesi 50. Kuruluş Yıldönümü Arkeoloji Bölümü Armağan Doğudan Yükeselen Işık Arkeoloji. ss. 69-84.

Ketin, İ. (1976). San Andreas ve Kuzey Anadolu Fayları arasında bir karşılaştırma. Türkiye Jeoloji Kurumu Bülteni, 19 , 149-154.

Konyar, E. (2008). Mübibbe Darga Armağan (Urartu Coğrafyasında 'Anttsal Kaya İșaretleri: İslevleri Üzerine Etno-Arkeolojike Bir Yaklaşım) (Edt: T. Tarhan, A. Tibet, E. Konyar). İstanbul: Sadberk Hanım Müzesi Yayınları.

Korkmaz, M. (2015). Floristical diversity and endemic plants of Çayırlı District (Erzincan/Turkey). Biological Diversity and Conservation, 8(3), 223-247.

Loon, M. N. V. (1966). Urartian art: Its distinctive traits in the light of new excavations. İstanbul: Uitgaven van het Nederlands Historisch-Archeologisch Instituut.

Marco Polo (2015). Marco Polo'nun geziler kitabı (Çev: Ö. Güngören). İstanbul: Yol Yayınları.

Osten, H. H. V. D. (1940). Neue Urartaelsche Bronze aus Erzincan. VI. International Kongress für Archaeologi 1939, Berlin, 225-229.

Özgüç, T. (1961). Altıntepe Kazıları-Excavations at Altıntepe. Belleten, XXV(98), 253-257.

Özgüç, T. (1963). Altıntepe'de Urartu Mimarlık Eserleri-The Urartian Architecture on the summit of Altıntepe. Anatolia 7.

Özgüç, T. (1966). Altıntepe I: Mimarllk. Anitlar ve Duvar Resimleri-Arcitectural Monuments and Wall Paintings. Ankara: Türk Tarih Kurumu Basımevi.

Özgüç, T. (1969). Altıntepe II: Mezarlar, Depo Binası ve Fildişi Eserler-Tombs, Storehouse and Ivories, Ankara.

Özgül, O. (2015). Erzurum Tortum'da Önemli Bir Urartu Kalesi: Kapıkaya. Trakya Üniversitesi Edebiyat Fakültesi Dergisi, 5(9), 69-92.

Pehlıvan, M. (1984). En eski çă̆lardan urartu'nun yıkıllşına kadar erzurum ve çevresi (Doktora Tezi). Atatürk Üniversitesi, Erzurum.

Pehlivan, M. (1991). Hayaşa (MÖ XV-XIII. Yüzynllarda Kuzey-Doğu Anadolu). Erzurum: Atatürk Üniversitesi Fen Edebiyat Fakültesi Yayınları.

Polat, P. ve Yalçın, F. (2020). Erzincan ili arazi kullanımının (2000-2018 yılları arası) corıne sistemi ile değerlendirilmesi. Doğu Coğrafya Dergisi, 25(44), 125-150.

Saraçoğlu, H. (1989). Doğu Anadolu Bölgesi. İstanbul: MEB Yayınları.

Tarhan, M.T. (1978). MÖ XIII. Yüzynlda Uruatri ve Nairi Konfederasyonlar (Basılmamış Doçentlik Tezi). İstanbul Üniversitesi Edebiyat Fakültesi, İstanbul.

Tarkan, T. (1974). Ana çizgileriyle Doğu Anadolu Bölgesi, Atatürk Üniversitesi 50. Yul Armağanı. Erzurum, ss. 7-22.

Torun, R. (2021). Cayırl ilçesi ve çevresinin eskiçağ tarihi (Yüksek Lisans Tezi). Erzincan Binali Yıldırım Üniversitesi, Sosyal Bilimler Enstitüsü, Erzincan.

Üngör, İ. (2018). Urartu Devleti'nin kuzey bölgesinde önemli bir kale: Tuzla kalesi. Akademik Tarih ve Düsünce Dergisi, 5(17), 93-129.

Üngör, İ. ve Özgül, O. (2016). Otlukbeli'nde tarihi ve arkeolojik araştırmalar. Kafkas Üniversitesi Sosyal Bilimler Enstitïsü Dergisi, (17), 267-289.

Yakar, J. (2012). Anadolu'nun Etnoarkeolojisi - Tunç ve demir çağlarnda kırsal kesimin sosyo-ekonomik yapısı (Çev: S. H. Riegel) (2. Basım). İstanbul: Homer Yayınları.

Yalçın, F. ve Polat, P. (2021). Erzincan Ovası'nda yer alan birikinti koni ve yelpazelerinin genel özellikleri, siniflandırılması ve antropojenik degradasyonu. Gaziantep University Journal of Social Sciences, 20(3), 1043-1068.

Zimansky, P. E. (1985). Ecologyand Empire, The Structure of the Urartian State. Chicago: Oriental Institute of the University of Chicago.

\section{EXTENDED ABSTRACT}

Eastern Anatolian studies are concentrated in and around Van due to the fact that it is the founding site of the Kingdom of Urartu. Then in the middle of the 20th century, it began to be concentrated in cities such as Erzurum, Malatya, and Elazıg. The first excavation work in Erzincan was carried out by Tahsin Özgüç in 1959 in Altıntepe, located on the Erzincan Plain, in 1959. This excavation has led historians to think that the Karaz and Urartian culture around Erzincan may have an important and intense impact. After the Altintepe excavations, which ended in 1967, there was no significant work on the Ancient Era in and around Erzincan until 1998. In 1998, surface surveys has been initiated by A.Ceylan. Archaeological and historical surface surveys conducted by Ceylan and his team have revealed very valuable results in the direction of understanding the history of the Erzincan region. The surface surveys carried out in all districts have provided the identification of numerous centers mentioned in the written documents, as well as been extremely useful for explaining the existence and localization of Early Iron Age principalities such as Diauehi. In addition, in the light of these studies have also been identified, a large number of castles, mounds, dams for irrigations, sanctuaries, necropolises, mine melting sites located in Erzincan from the Chalcolithic Period to the Middle Ages. 
It has been understood by these studies that the east of Erzincan contains important archaeological and historical structures in many ways since the Chalcolithic Period. A large number of centers have been identified in deepened surface surveys in Tercan, Çayırlı and Otlukbeli districts. Architectural structures, sanctuaries, pottery from these centers have been studied. When these are evaluated, the presence of traces of settlements in the region has been revealed since the Chalcolithic Period. Especially in places such as Erzurum, Elazığ, Malatya, Karaz Culture, which has been found to be present in places such as Erzincan, has also been observed to have dense traces in Erzincan. It is understood that the east of Erzincan was located within the borders of Diauehi in the Early Iron Age. In the Urartian period, besides the well-known centers such as Şirinli Castle, Çadırkya / Pekeric, Yollarustu Castle, there were also many centers such as Tuzla Castle, Stratasslar Castle. However, from the earliest times it was determined that the region was located on an extremely important road network from a military, political and commercial point of view, except for the settlement culture. Studies have confirmed that the region has a relationship with the cultures of the South Caucasus and Inner Asia from the earliest times. Different types of ceramics and types of graves found in Tercan, Çayırlı and Otlukbeli districts are important to support this opinion.

In the research conducted in Çayırlı district; The fact that settlements and other historical and archaeological centers belonging to different periods ranging from the Chalcolithic Era to the Middle Ages have been identified has revealed the necessity of considering this region separately. In the light of surface research, this area has been evaluated as a master's degree subject. In addition, some new definitions and opinions have been put forward in this study.

The fact that the region is located at an altitude of above sea level and has a mountainous and hilly geography has affected its climatic features. There are quite fertile agricultural lands and plains consisting of wide plains in the region. Çayırlı district and its surroundings are very rich in hydrographic terms due to the fact that the Karasu River passes through here. The Black Sea (Euphrates) River has been influential in shaping the socio-economic structure of the region.

As part of surface surveys, numerous castles founded by the Urartians or formerly existing and modified by the Urartians have been found in the region. This has shown us that the Urartian State was active in the region during the Iron Age and paid attention to this region for many reasons. The Sırataşlar Castle, located in the district, has been the best example of this cultural spread. We think that the Sirataşlar Castle has the quality of being a garrison castle during the Urartian period due to its location on natural roads and proximity to Altintepe Castle.

Çadırkaya/Pekeric Castle, located in Çadırkaya village, which is very close to Çayırlı district and is located in Tercan district, was inhabited in the Iron Age and the Middle Ages, Tuzla Castle was inhabited in the Early Iron Age and the Middle Iron Age. In the Middle Ages, it was understood that Çayırlı and its surroundings were inhabited quite intensively. In addition, it was revealed as a result of our studies that Çayırlı and its surroundings are on the route of natural and historical roads. The castles that have been built on the roads that we have identified show them. The district is located in the center of the roads reaching from Erzurum to the inland regions of the Eastern Black Sea Region. 


\section{EKLER}

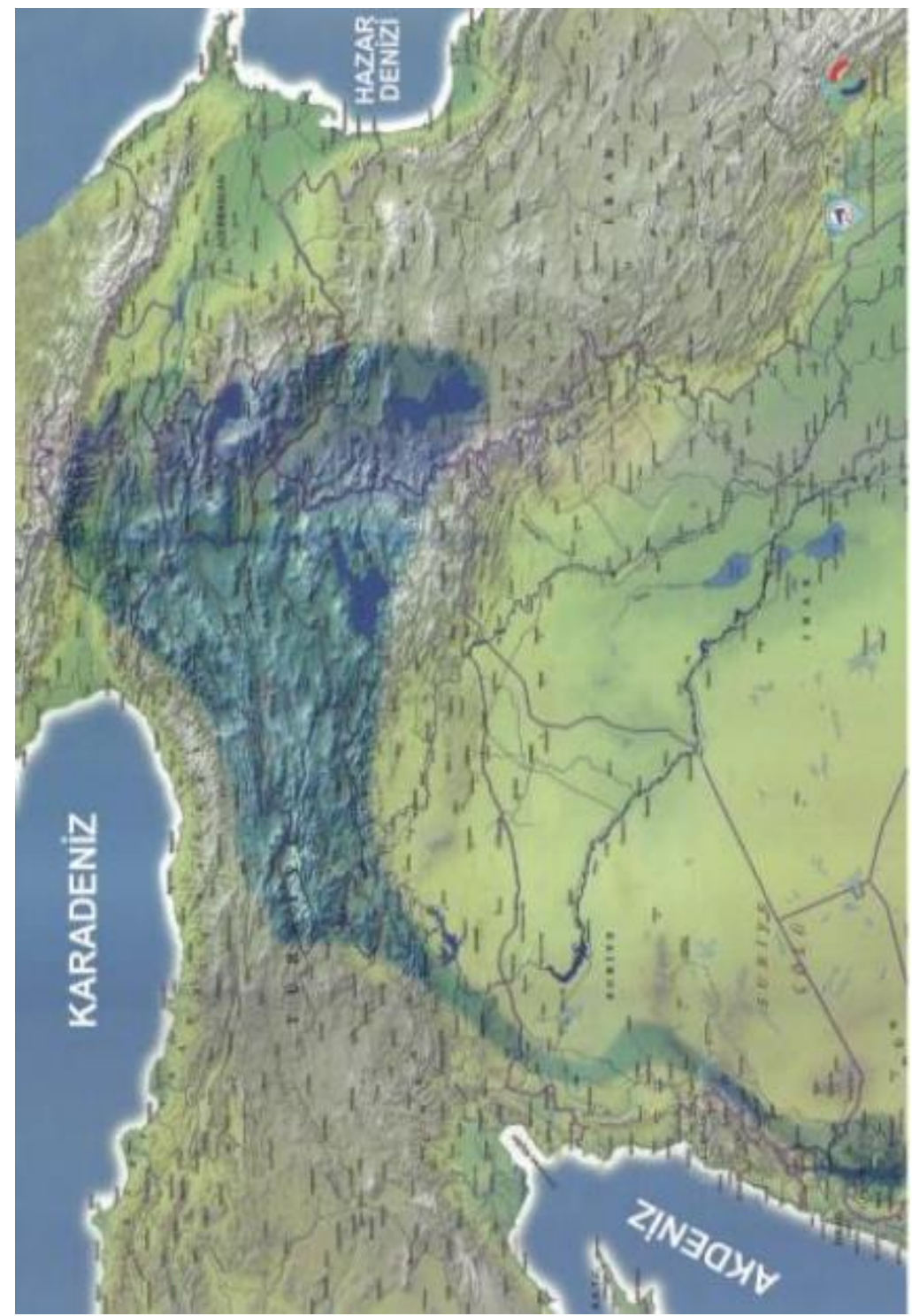

Harita 1. Karaz Kültürü Yayılım Haritası(A.CEYLAN Arşivi) 


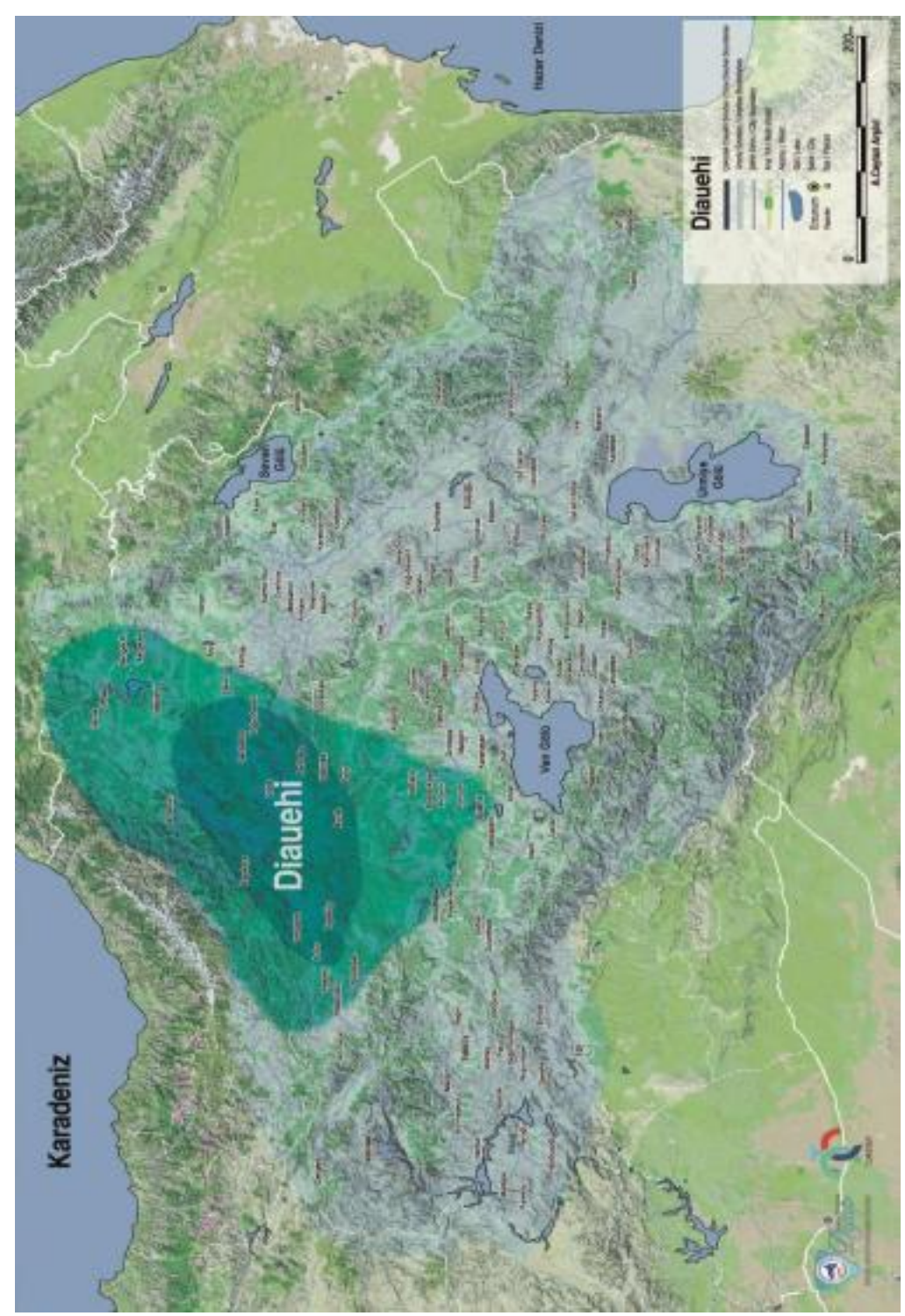

Harita 2. Daya(e)ni/Diau(e)bi Yayıllm Haritası (A. Ceylan Arşivi) 
ÜNGÖR ve TORUN

Erzincan İli Çayırlı İlçesinde Tespit Edilen Tarihi ve Arkeolojik Merkezlerin Değerlendirmesi

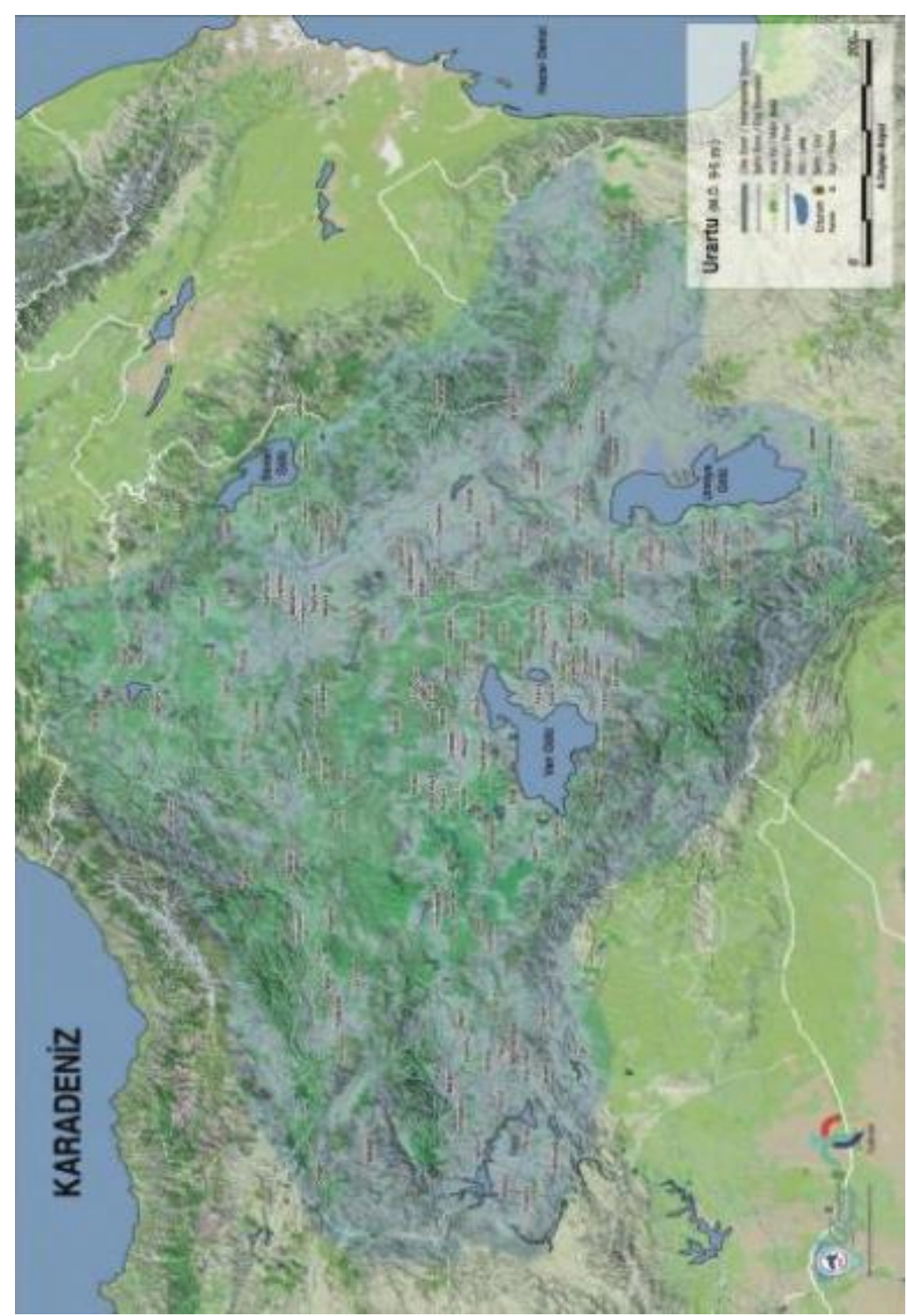

Harita 3. Urartu Yayıllm Haritası (A. Ceylan Arşivi) 


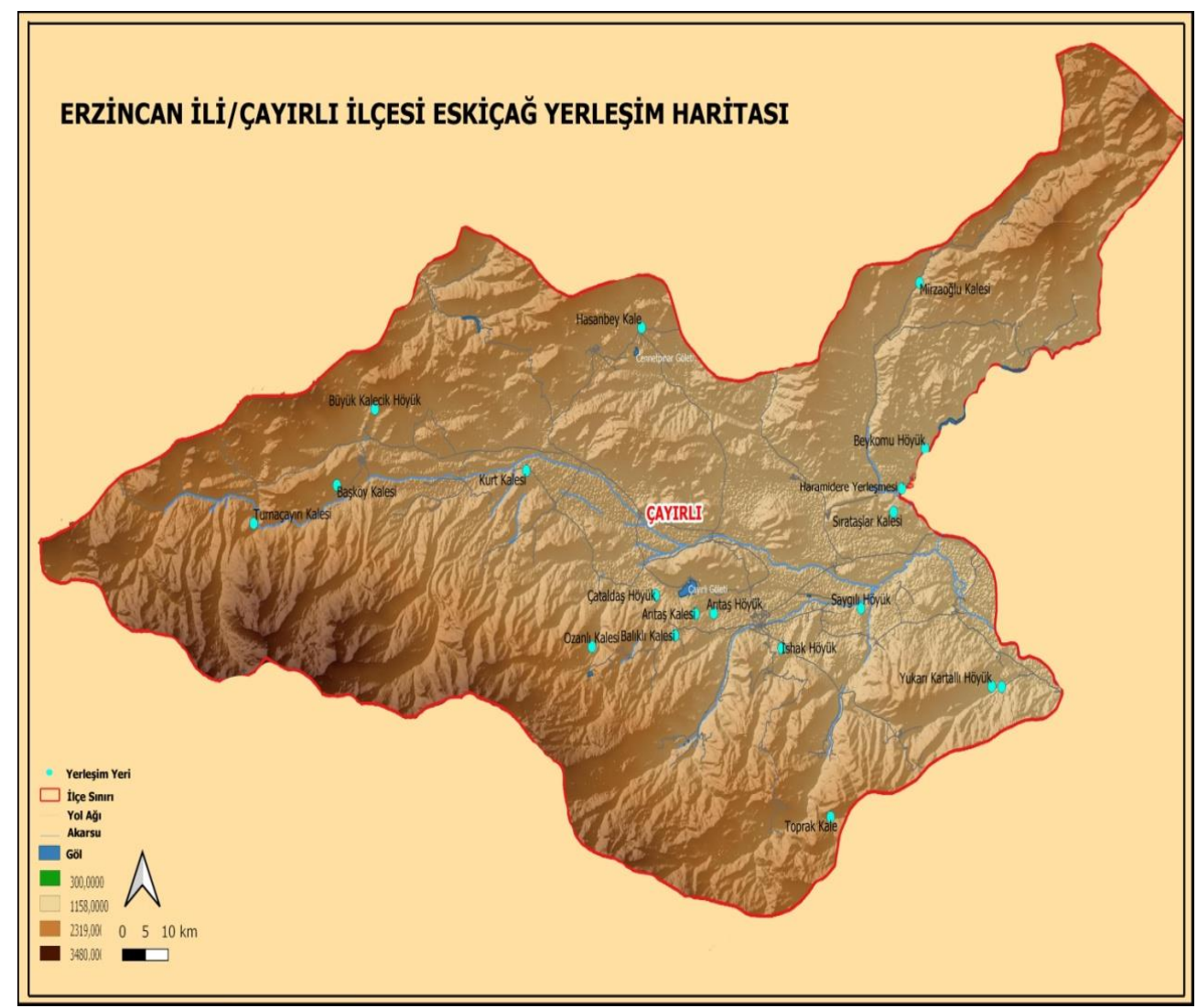

Harita 4. Cayırlı İlcesi Eskiçağ Yerleşim Haritası

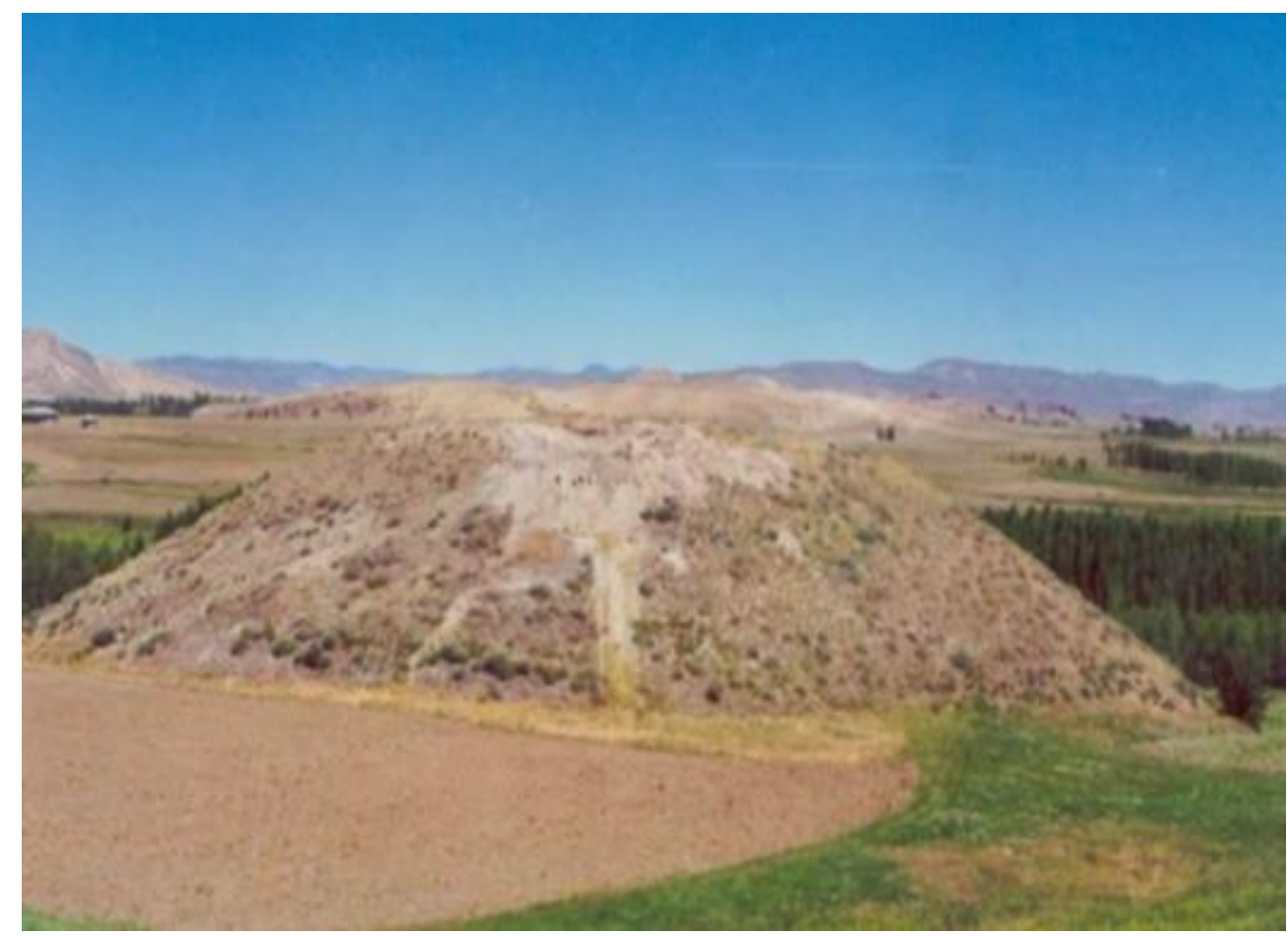

Foto 1. Saygzlı Höyük (A. Ceylan Arşivi) 


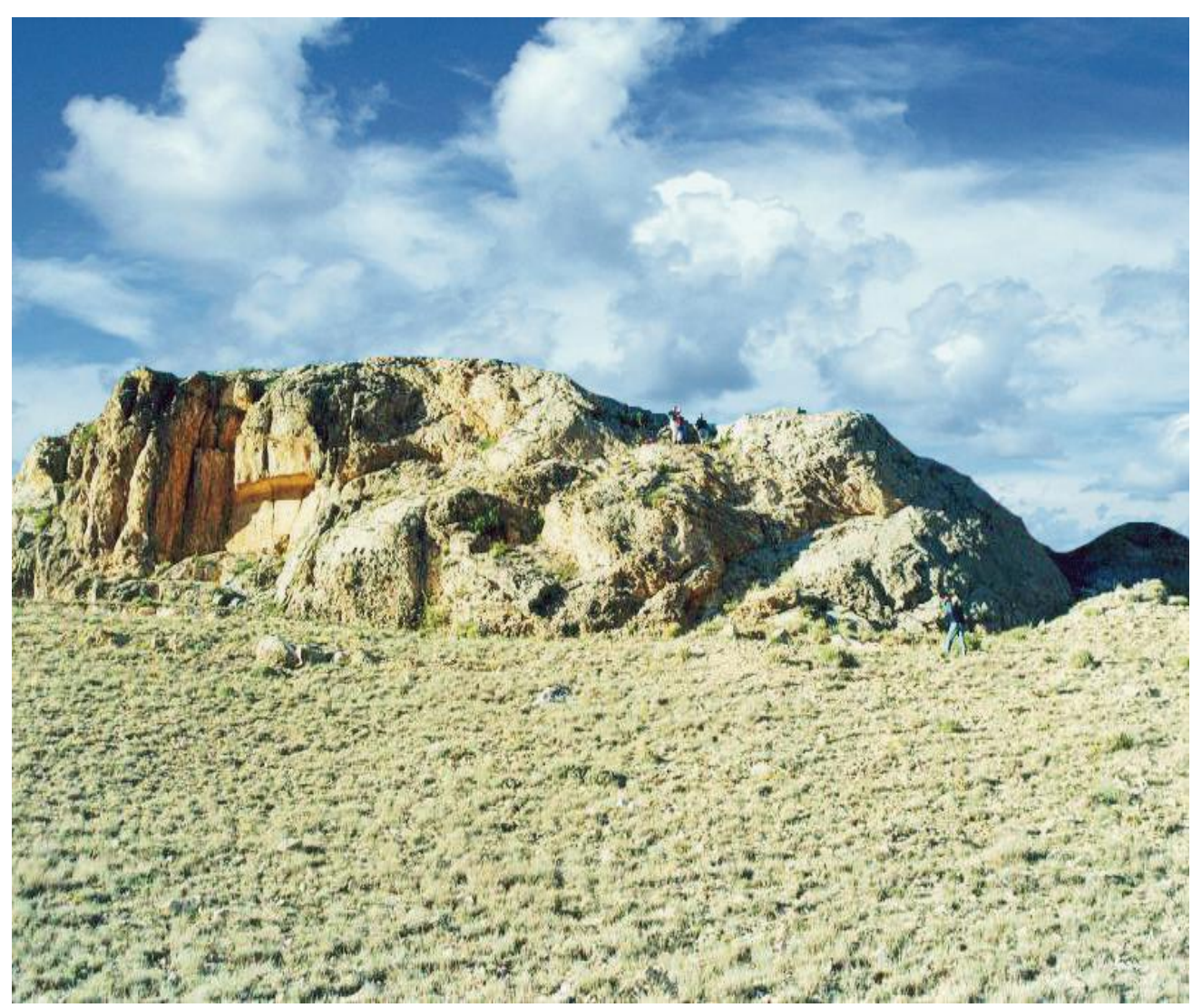

Foto 2. Siratașlar Kalesi

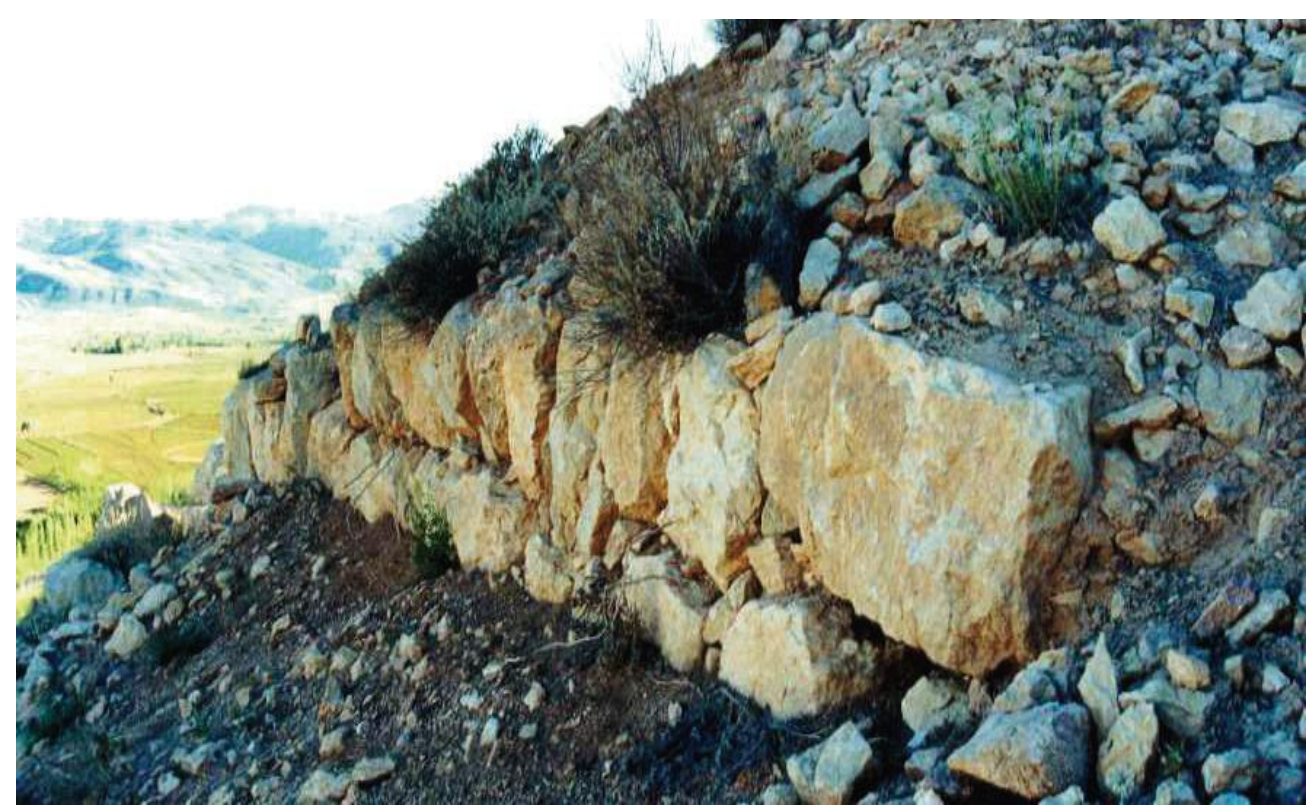

Foto 3. Sirataslar Kalesi 


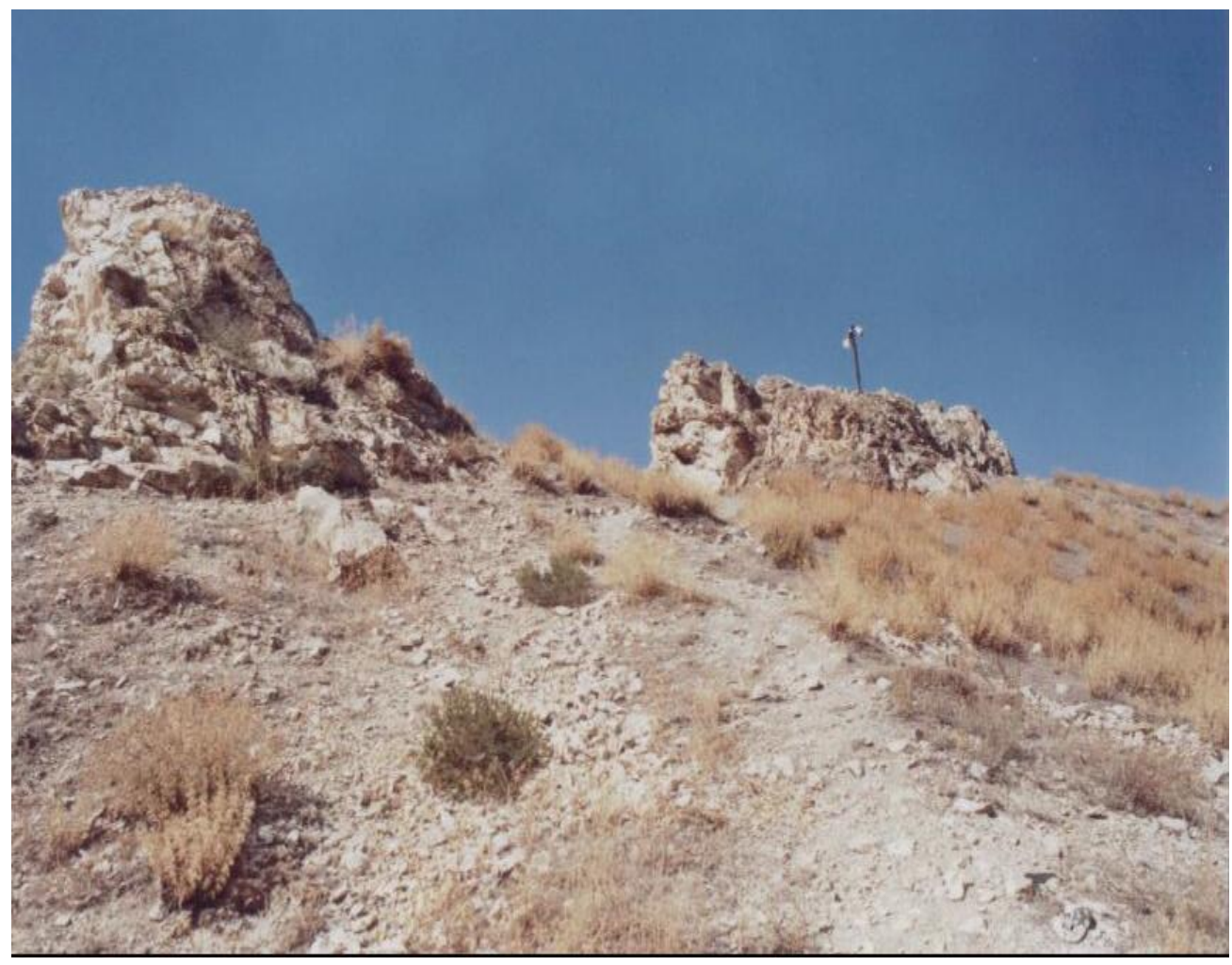

Foto 4. Balıklköy Kalesi

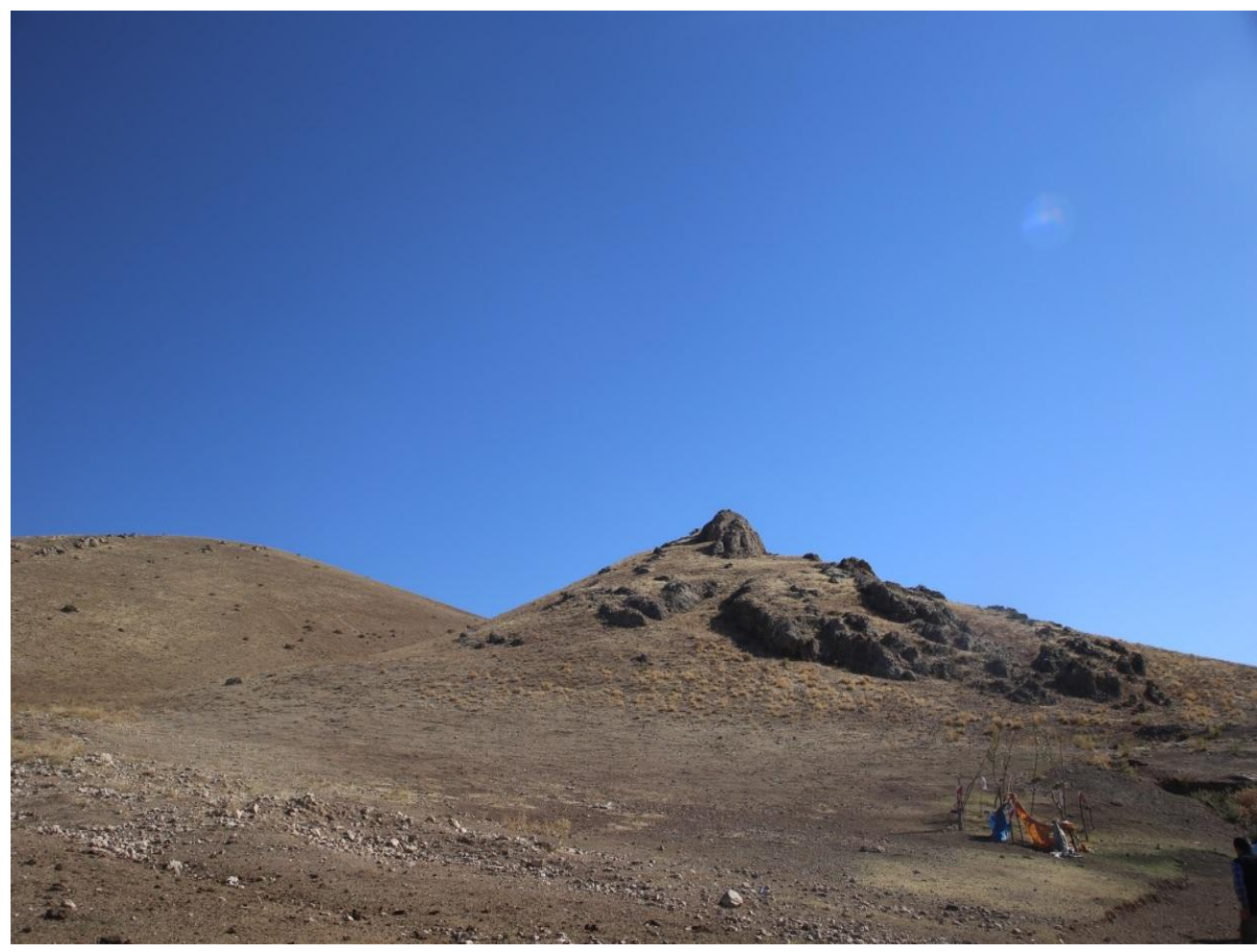

Foto 5. Tu₹la Kalesi 
ÜNGÖR ve TORUN

Erzincan İli Çayırlı İlçesinde Tespit Edilen Tarihi ve Arkeolojik Merkezlerin Değerlendirmesi

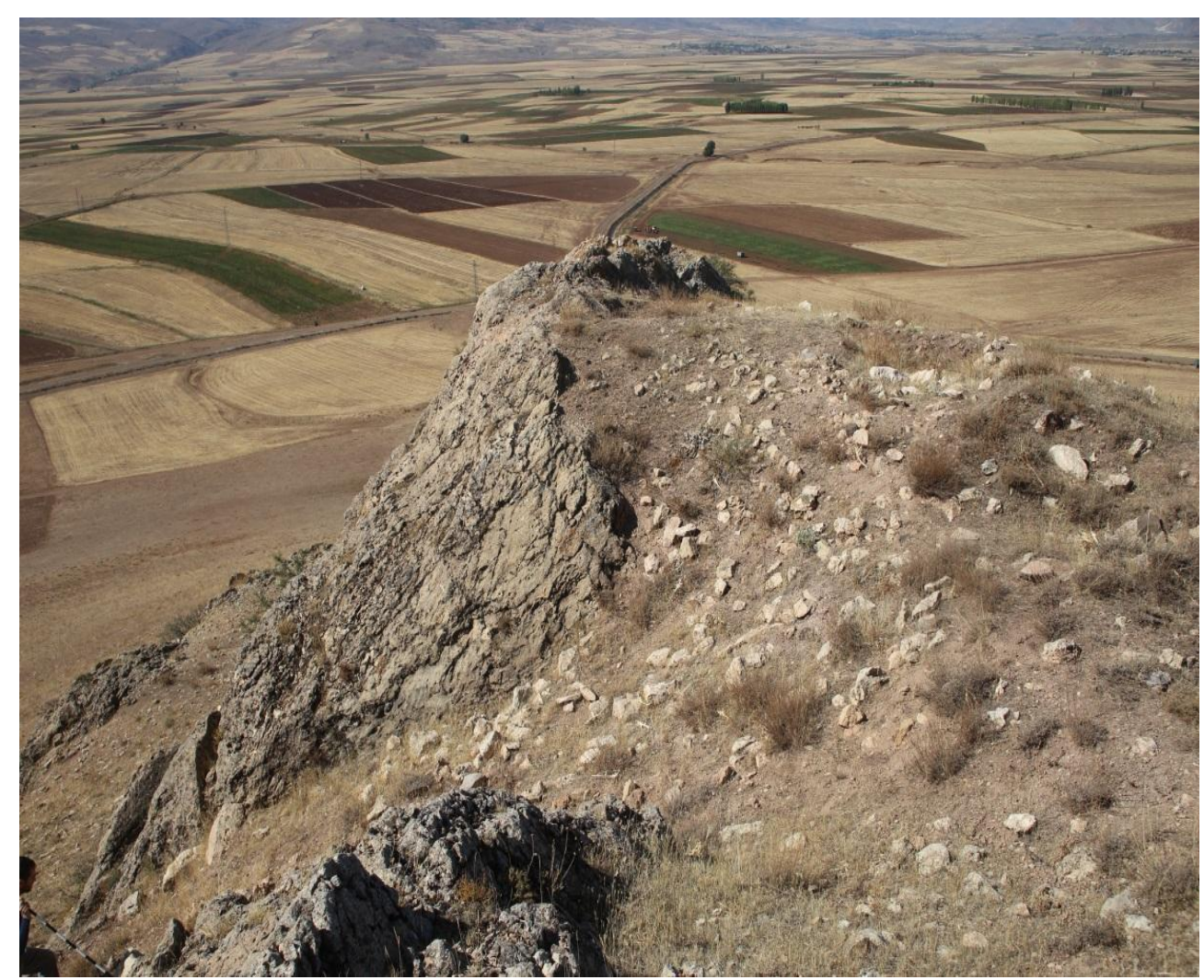

Foto 6. Tuqla Kalesi

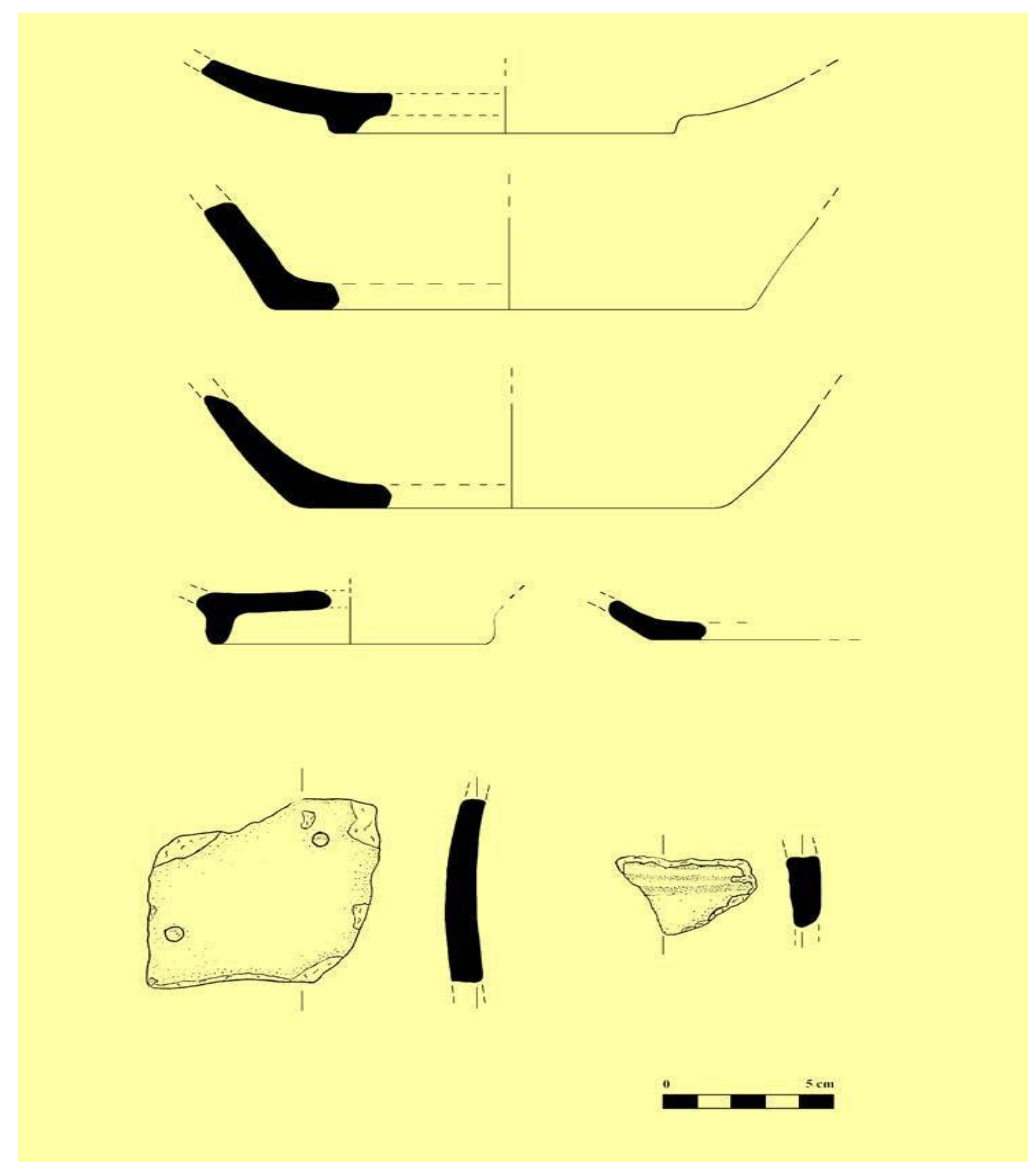

Çizim 1. Tuそla Kalesi Keramikleri 


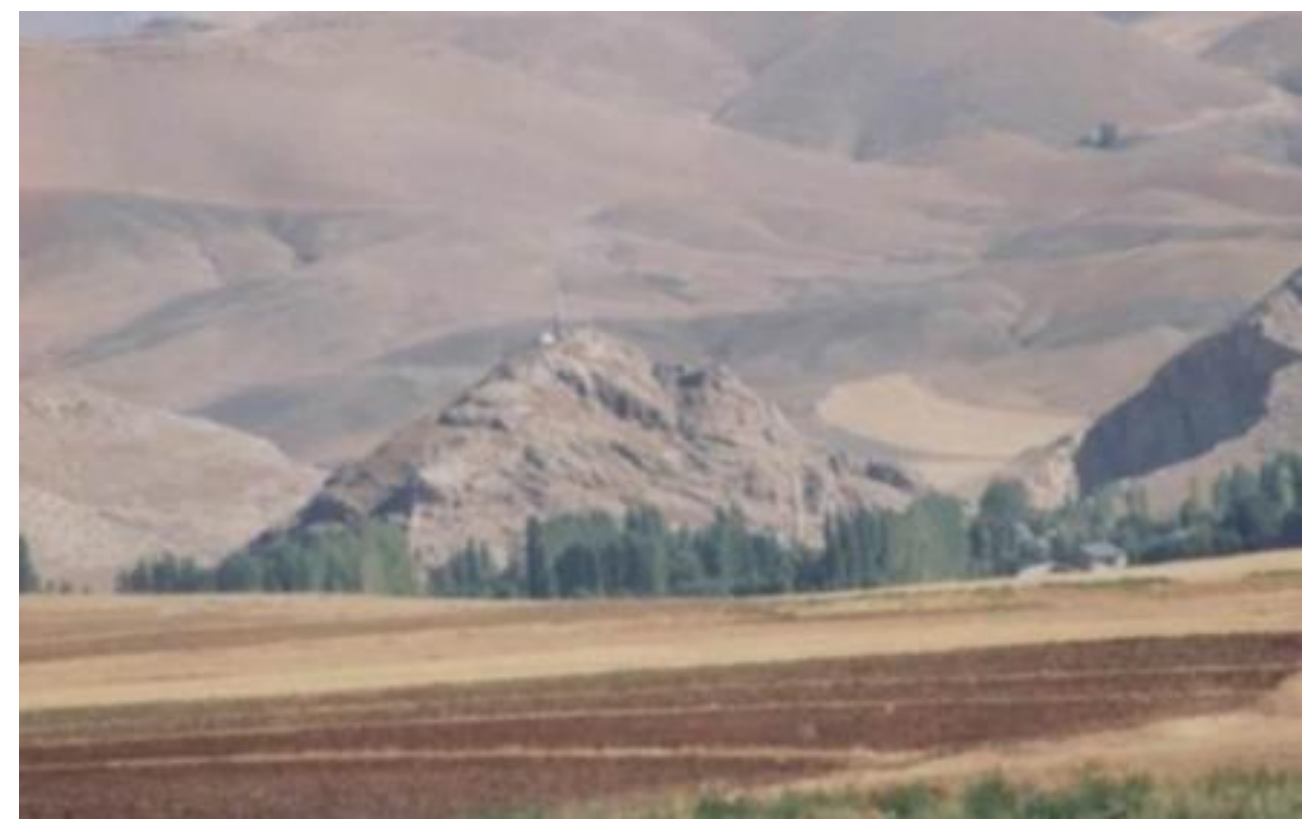

Foto 7. Cadirkaya (Pekeric) Kalesi

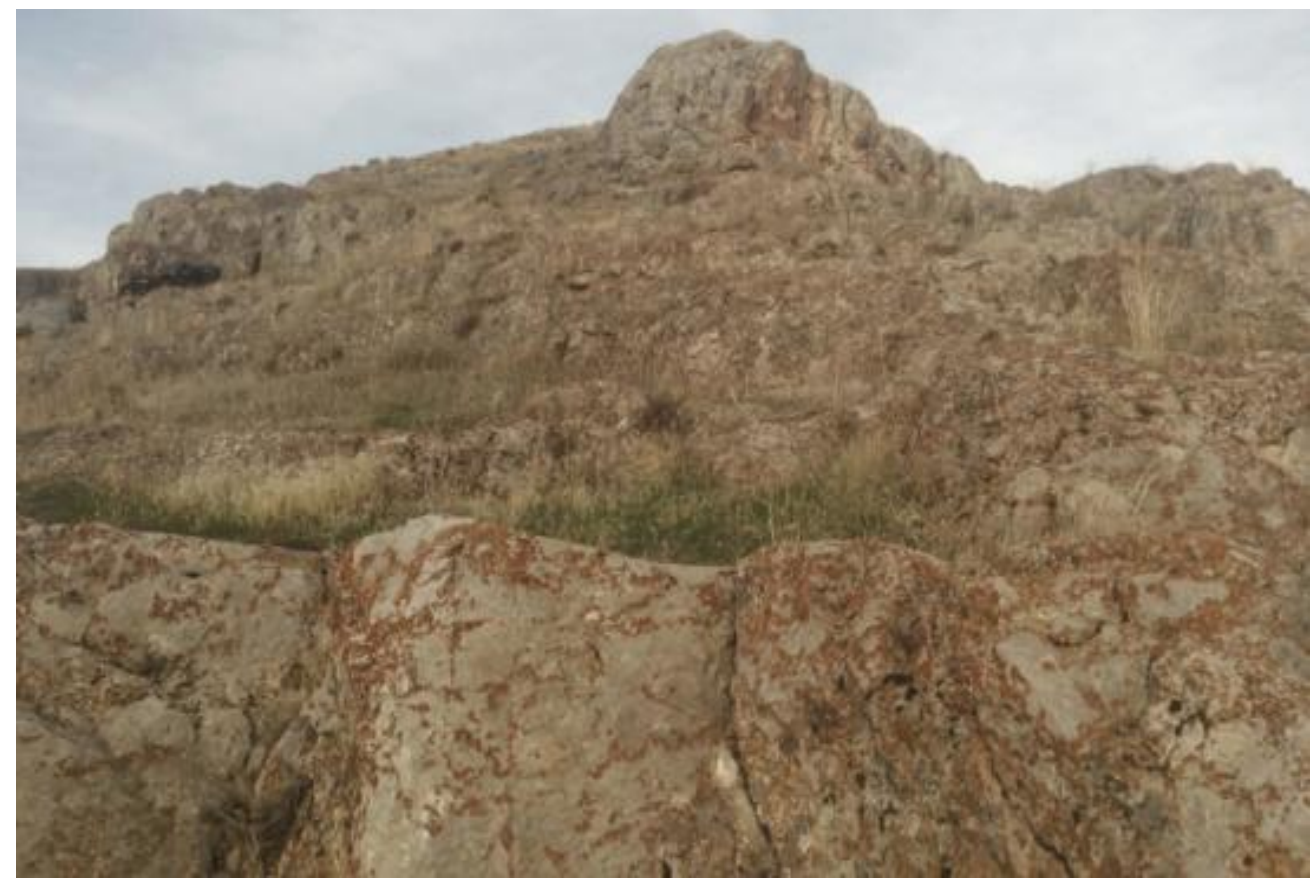

Foto 8. Cadirkaya (Pekeriç) Kalesi 


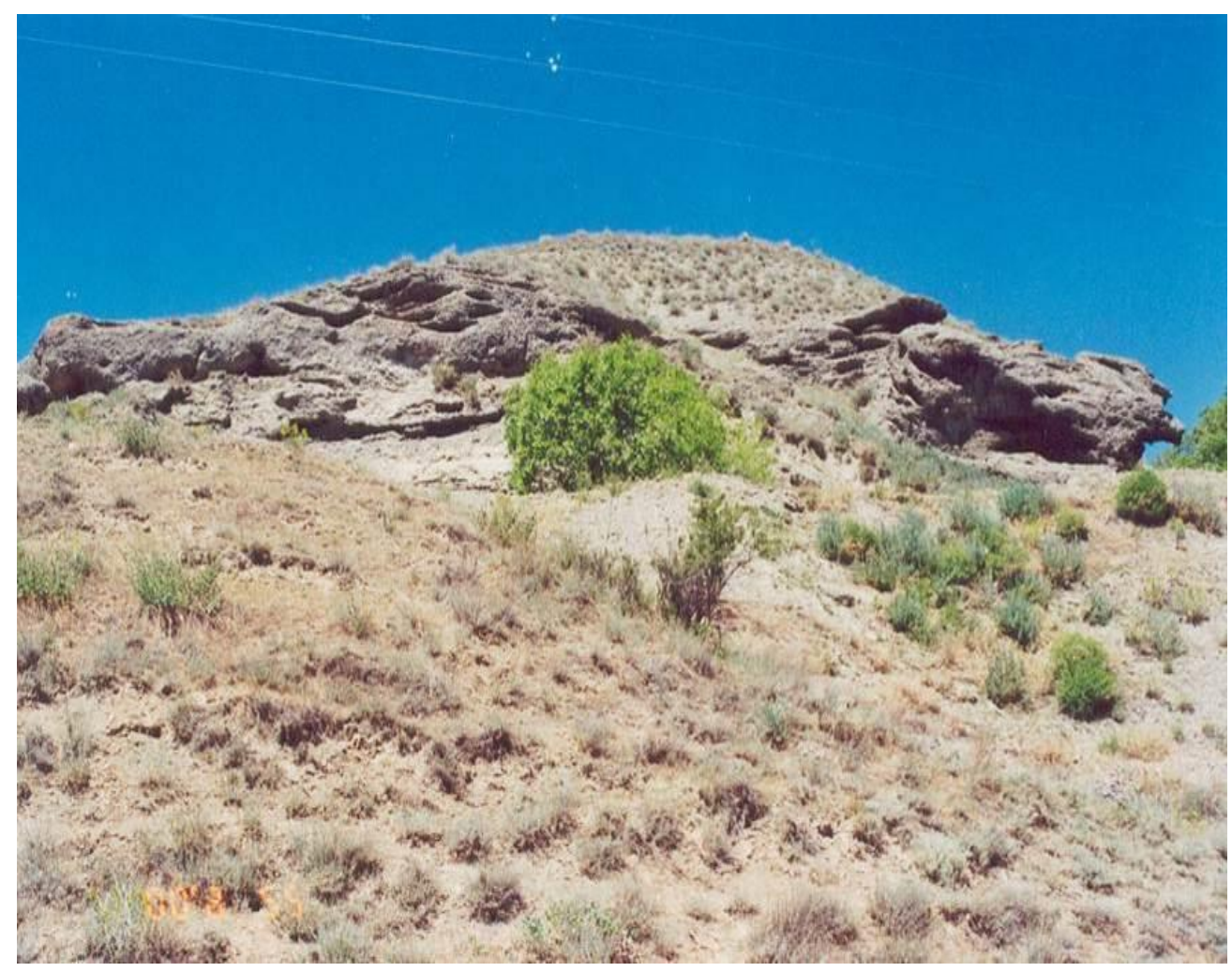

Foto 9. Beykomu Höÿ̈k

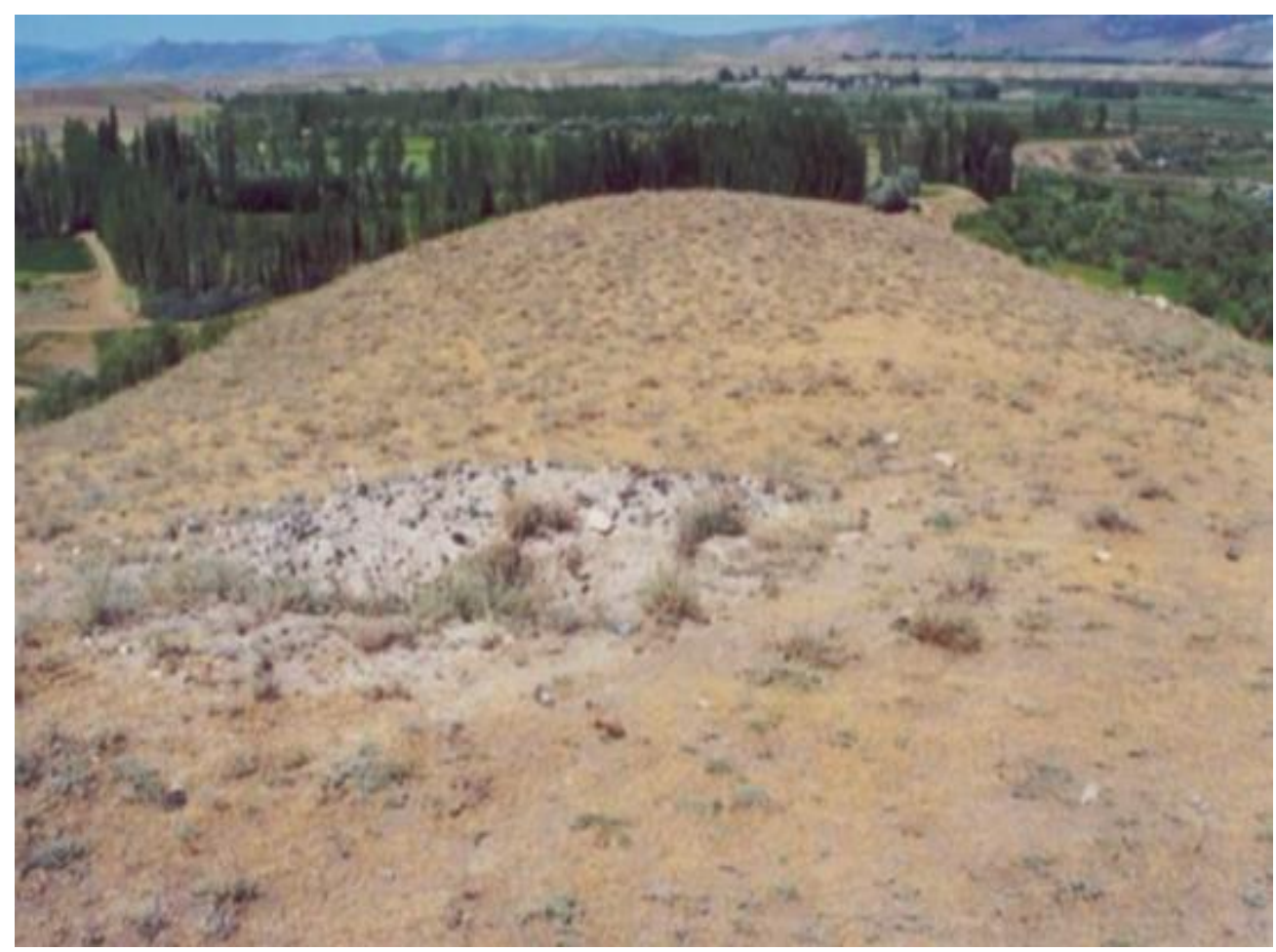

Foto 10. Haramidere Yerlesmesi 